\title{
Interregional comparison of benthic ecosystem functioning: Community bioturbation potential in four regions along the NE Atlantic shelf
}

\author{
Gogina Mayya 1, * , Zettler Michael L. ${ }^{1}$, Vanaverbeke Jan ${ }^{2}$, Dannheim Jennifer ${ }^{3,4}$, Van Hoey Gert ${ }^{5}$, \\ Desroy Nicolas ${ }^{6}$, Wrede Alexa ${ }^{3,4}$, Reiss Henning ${ }^{7}$, Degraer Steven ${ }^{2}$, Van Lancker Vera ${ }^{2}$, Foveau \\ Aurelie ${ }^{6}$, Braeckman Ulrike ${ }^{8}$, Fiorentino Dario ${ }^{3,4}$, Holstein Jan ${ }^{9}$, Birchenough Silvana N.R. ${ }^{10}$
}

${ }^{1}$ Leibniz Institute for Baltic Sea Research, Seestraße 15, 18119 Rostock, Germany

2 Royal Belgian Institute of Natural Sciences, Operational Directorate Natural Environment, Vautierstraat 29, B-1000 Brussels, Belgium

${ }^{3}$ Alfred Wegener Institute, Helmholtz Centre for Polar and Marine Research, P.O. Box 120161, D-

27570 Bremerhaven, Germany

${ }^{4}$ Helmholtz Institute for Functional Marine Biodiversity at the University of Oldenburg (HIFMB),

Ammerländer Heerstraße 231, Oldenburg 26129, Germany

${ }^{5}$ Flanders Research Institute of Agriculture, Fishery and Food, Ankerstraat 1, 8400 Oostende, Belgium

6 Ifremer, Laboratoire Environnement et Ressources Bretagne nord, 38 Rue du Port Blanc, 35800

Dinard, France

${ }^{7}$ Faculty of Biosciences and Aquaculture, Nord University, 8049 Bodø, Norway

${ }^{8}$ Marine Biology Research Group, Ghent University, Krijgslaan 281/S8, 9000 Gent, Belgium

${ }^{9}$ Focke \& Co., Siemensstraße 19, 27283 Verden, Germany

${ }^{10}$ CEFAS Lowestoft Laboratory, Pakefield Road, Lowestoft, Suffolk NR33 OHT, United Kingdom

* Corresponding author : Mayya Gogina, email address : mayya.gogina@io-warnemuende.de

\begin{abstract}
:
Bioturbation is one of the key mediators of biogeochemical processes in benthic habitats that can have a high contribution to seafloor functioning and benthic pelagic coupling in coastal waters. Previous studies on bioturbation were limited to point locations and extrapolations in single regions, but have not accounted for regional differences under changing environmental conditions, though there are indications that species contributions will differ across regions or with biotic and abiotic context. To capture those differences and assess global patterns and commonalities, multi-regional analyses are imperative. Here for the first time, bioturbation potential (BPc), a functional indicator of benthic community bioturbation, was estimated based on macrofauna data from four regions (i.e. German Baltic Sea, German North Sea, Belgian part of the North Sea and the Eastern English Channel). For each region and sediment type we identified key species contributing to BPc. Comparison within and across regions demonstrated regional differences, and both overlap and mismatch between species that are functionally important and those that are dominant in biomass. Knowledge on the functionally important species is crucial when management objectives include the protection of certain ecosystem functions. Available environmental layers were used as predictors to model the spatial distribution of BPc for each area and to explore the underlying drivers of differences. Random forest models were trained using as response variables either i) BPc initially calculated per station; or ii) BPp - the species-specific contribution to BPc - for key species
\end{abstract}


(with subsequent summation of their predicted full-coverage distributions to BPc). Maps of BPc distribution predicted by random forest were compared with those generated using natural neighbour interpolation. Overall, derived BPc values increased towards the German parts of the North and Baltic Seas. The relevance of $\mathrm{BPc}$ for ecosystem processes and functions, however, vary with biotic and abiotic settings. Results revealed a strong association of BPc with species diversity and region, but less with sediment grain size. A large range of BPc occurred when species richness was low. This suggests that the provisioning of high bioturbation activity is possible also under low diversity, where it is vulnerable due to reduced resilience. The executed multi-regional analysis allowed identifying regional differences in performance of macrofauna, suggesting the need for region-specific conservation and management strategies.

\section{Highlights}

First multi-regional analysis of macrofauna community bioturbation potential $\left(\mathrm{BP}_{\mathrm{c}}\right)$. $>$ Functionally important key species differ regionally and between sediments. Overall $\mathrm{BP}_{\mathrm{c}}$ values decreased from the Baltic Sea towards Eastern English Channel. Relevance of $\mathrm{BP}_{\mathrm{c}}$ for ecosystem functions vary with biotic and abiotic settings. Results accent the need for region-specific conservation and management strategies.

Keywords: Macrofauna traits, Bioturbation index, Biogeographic comparison, Species distribution modelling, Biodiversity attributes, Ecosystem management 


\section{Introduction}

Ecosystem properties are influenced by alterations in biodiversity (Snelgrove et al., 2018; Thomsen et al., 2019). Benthic systems regulate energy in marine ecosystems and grant valuable products and ecological services to human society (Paterson et al., 2012). Benthic macrofauna is important in food webs, sediment transport, bentho-pelagic coupling, nutrient cycling and other biogeochemical processes, both directly or indirectly, through regulating properties for microorganisms, enhanced physical exchange and physiological factors (Griffiths et al., 2017). Thus, presence or absence of specific traits due to species extinctions, invasions and changes in number of individuals or biomass loss will modify their contribution to ecosystem functioning. A number of previous studies suggested that species contributions will differ across regions and/or with under different environmental conditions (Godbold and Solan 2013; Wohlgemuth et al. 2017). Bioturbation is one of the main components of benthic-pelagic coupling in marine coastal ecosystems: it comprises all transport processes carried out by animals that directly or indirectly affect sediment matrices, including both particle reworking and burrow ventilation (Kristensen et al., 2012). Quantitative estimates of bioturbation are useful for comparison of varying effects of benthic organisms on ecosystem functioning, including those related to altered oxygen supply, chemical gradients within the sediment and solute fluxes at the sediment-water interface, microbial degradation rates, sediment and contaminant transport (Haider et al., 2019).

The bioturbation potential of a community (BP , Solan et al., 2004; ; Birchenough et al. 2012; Birchenough et al. 2013; Queirós et al., 2013) is one of the few existing quantitative trait-based indicators for ecosystem functioning. It combines particular traits of species (e.g., sediment reworking and mobility) with species abundance and biomass to infer species' function as bioturbator (Queirós et al., 2013). Hence, it can be calculated based on largely available benthic macrofauna data, in contrast to rarely and sporadically available data on bioturbation depth, bio-mixing models and biodiffusion coefficients measured in experimental set-ups (e.g. Soetaert et al., 1996; Morys et al., 2016, but see also the global bioturbation dataset recently published by Solan et al., 2019). These types of indicators, linked with pressures in a spatially explicit manner and at larger geographical scales, are often required for marine spatial planning and management purposes (Galanidi et al., 2016; Reiss et al., 2015). Although $\mathrm{BP}_{\mathrm{c}}$ does not take into account context-specific bioturbation activities (Gogina et al., 2017; Aneiros et al., 2018), it has been successfully related to organic matter mineralisation processes (Braeckman et al., 2014) as well as fluxes of nutrient-species and oxygen across the sediment-water interface (Wrede et al., 2017). Even though many studies have extrapolated from point sources (Gogina et al., 2017; Meyer et al., 2019), they did not 
account for interregional differences in activity or differences in behavior between locations or over time under changing conditions, stirring up our motivation to perform the first biogeographic comparison of $\mathrm{BP}_{\mathrm{c}}$ patterns across regions.

The general goal of this study is to amplify our knowledge on $\mathrm{BP}_{\mathrm{c}}$ by a comparative case study on large spatial scale comprising four regions along the European Shelf. This is especially necessary as this index is gaining more and more popularity, and even though $\mathrm{BP}_{\mathrm{c}}$ was not invented for linking it with ecosystem functioning (Solan et al. 2004), it does link to it well in some environments, while in others it does not. The explanation is, that in the cases it does, $\mathrm{BP}_{\mathrm{c}}$ reflects a process (e.g. particle displacement) that significantly contributes to the investigated ecosystem function, while in other areas it doesn't: e.g. fauna can be not (very) important (for mineralization processes) in coarse permeable sediments because of the advective currents going through the sediment, overruling biological transport effects (Braeckman et al. 2014). Nevertheless, the $\mathrm{BP}_{\mathrm{c}}$ seems to have an additional value as ecological indicator in terms of assessing function, rather than only abundance or biomass.

Here we attempt to estimate how variations in sediment composition and inhabiting fauna could potentially affect the spatial distribution of $\mathrm{BP}_{\mathrm{c}}$, and hence the effect of macrofaunal communities on benthic biogeochemical processes. Comparing $\mathrm{BP}_{\mathrm{c}}$ and key contributing species across biogeographical zones might reveal potential consequences of natural and anthropogenic pressures on these ecosystems. To obtain full-coverage maps for each region, spatial modelling was based on observational biological data (disregarding temporal variation) linked to available sets of environmental parameters (Reiss et al., 2015). Thus, in order to assess spatial distribution of the processing, and how $\mathrm{BP}_{\mathrm{c}}$ will vary with habitat type, this work aims to: (1) estimate $\mathrm{BP}_{\mathrm{c}}$ and identify the key species contributing most to bioturbation in each region and in different sediment types; (2) assess the regional spatial differences and variability of ecosystem functioning expressed by modelled $\mathrm{BP}_{\mathrm{c}}$; and (3) disentangle the drivers influencing those differences.

\section{Materials and methods}

\subsection{Study regions}

In order to account for regional differences, we focussed on four study sites located in the Baltic and the Atlantic biogeographical regions on the continental shelf, including the German part of the Baltic Sea (DEBS), the German part of the North Sea (DENS), the Belgian part of the North Sea (BENS) and the Eastern 
English Channel (ENCH) (see the map in Supplementary material S1 for stations locations, and Table 1). Apart from regional proximity and availability of data, this choice of regions was expected to be particularly informative due to rather broad range of changing environmental conditions, including transition from north to south and from enclosed brackish Baltic Sea to more open offshore and exposed areas. Additionally, all four regions are sufficiently well studied (data availability) to allow meaningful interpretation of broad findings without disregarding the region-specific context. Moreover, the regions are located along the coastal areas that experience increasing pressure from both climate change and various human activities.

\section{The German part of the Baltic Sea}

The Baltic Sea is a semi-enclosed sea connected to the North Sea by two narrow shallow straits (the Belt Sea and the Sound). The restricted water exchange through the straits shapes environmental conditions in the entire Baltic Sea. It is highly stratified by strong vertical salinity and temperature gradients. Halocline depth is controlled by freshwater runoff, wind-induced mixing and advection and varies from $10 \mathrm{~m}$ to 30 $m$ in shallower regions (Dargahi et al., 2017). In the south-western Baltic Sea (study area - $14800 \mathrm{~km}^{2}$, average depth - $19 \mathrm{~m}$ ) sedimentary habitats are mainly shaped by postglacial processes. Shallow areas along the shore and on top of the offshore glacial elevations are characterized by a mosaic of rocks, till, gravel and coarser sands. The substrate is finer with increasing water depth. Organic-rich muddy sediments dominate in the basins and deeper part of trenches (Darr et al., 2014). Near-bottom salinity and oxygen conditions are the main drivers of species richness and composition of benthic macrofauna communities in the area (Zettler et al., 2017). The overall salinity declines from 20-25 in the western part of Kiel Bay towards 7 in the eastern Pomeranian Bay. The water exchange between the western Baltic and the Baltic Proper is inhibited by the Darss and Drodgen Sills, causing highest temporal variability of salinity in the western part of the study area. Aperiodic seasonal oxygen depletion events occur in the deeper areas of the Kiel Bay, the Bay of Mecklenburg and in the Arkona Basin, and have negative effects on the diversity and density of soft-bottom fauna (Arntz, 1981).

\section{The German part of the North Sea}

The study area in the south-eastern North Sea region is known as the German Bight. It covers an area of

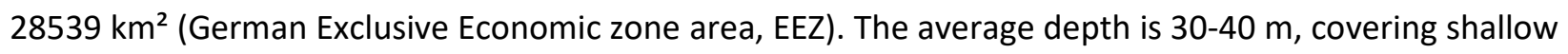
parts (e.g. the Amrum Bank) with $10 \mathrm{~m}$ depth and deeper areas (up to $60 \mathrm{~m}$ depth) in the Helgoland deep trench and the most northern tip of the German EEZ. In its shallower regions, the water column is generally well mixed, due to wave action and tidal currents, while deeper parts are stratified which results 
in a high seasonal variability of bottom waters in different geographical regions. Most of the primary production occurs in the nutrient rich, well-mixed waters of the shallow southern parts and along the eastern coast. Salinity ranges between 24 in the river estuary areas and 35 in the offshore German waters. The study area is dominated by sandy and muddy-sandy sediments (Laurer et al., 2012). Muddy substrate occurs mainly in the Wadden flats and in the glacial valley of the Elbe River. In the shallower areas along the Elbe glacial valley, i.e. along the northern and eastern Frisian coast, sediments are patchy distributed with fine to coarse sand, gravel, cobble and stones. Temperature, sediment and depth are the most important environmental parameters shaping the spatial and temporal distribution of the macrofauna communities (Callaway et al., 2002; Van Hoey et al. 2004). The Dogger Bank, located at the tip of the German EEZ, represents a natural border between the deeper parts of the central North Sea and the shallower German Bight and therefore also acts as a transition zone of habitats dominated by southerly and northerly distributed species (Zettler et al., 2018).

The Belgian part of the North Sea

The Belgian part of the North Sea (BENS; $3600 \mathrm{~km}^{2}$ ) is the most south-western part of the Southern Bight of the North Sea and has a maximum depth of $46 \mathrm{~m}$. This area is characterized by the presence of four isolated sandbank systems (Coastal Banks, Flemish Banks, Zeeland Banks and Hinder Banks) situated 10$30 \mathrm{~km}$ offshore, greatly contributing to the heterogeneity of the sea floor (Degraer et al., 2006). Sediments, and related benthic communities, in the BENS range from oxygen-stressed muddy sediments close to the shore to well oxygenized permeable, coarse sands and relatively small gravel beds further offshore (Braeckman et al., 2014; Montereale-Gavazzi et al., 2018; Breine et al., 2018). The offshore water column is composed of north-eastward flowing Atlantic water affected by freshwater discharges of several estuaries (rivers Seine, Somme, Scheldt and Rhine/Meuse (Lancelot et al., 1991; Yang, 1998; van Bennekom and Wetsesteijn, 1990), while the more near-shore waters are affected by freshwater outflows and residual gyre as a consequence of the discharge from the Western Scheldt river estuary (Arndt et al., 2011). The shallowness of the area, in combination with strong tidal currents results in a fully mixed water column (Simpson, 1994).

\section{The Eastern English Channel}

The English Channel (study area - $13927 \mathrm{~km}^{2}$ ) is a shallow epicontinental sea influenced by the Atlantic Ocean to the west and connected to the North Sea through the Dover Strait. Water masses may transit between the two marine areas, but only around $10 \%$ of water that enters the North Sea flows via the English Channel, whereas the main outflow occurs through north-eastern open boundary. In the eastern 
part of the Channel, tidal current strengths increase from 1.5 to 3 knots from the south to the northeast as the narrower part of the Dover Strait. Flow velocity decreases in the southern North Sea where it does not exceed 2 knots (S.H.O.M., 1968). Variations in the speed of the tidal current create a sedimentary gradient (Larsonneur et al., 1982). Pebbles and gravels prevail in the open sea, whereas coastal areas are dominated by large homogeneous sand banks and associated channel systems. The water quality is largely influenced by two main estuaries: the Seine estuary in the south-west, and the Scheldt delta in the northeast. Depending on the direction, intensity and duration of the wind, the plume of both rivers can reach the Dover Strait zone and modify the water salinity up to 2-3 miles off the French coasts (Brylinski et al., 1991). Other smaller rivers (i.e. Somme, Authie, Canche, Liane, Aa and Yser) and runoff from sea cliffs contribute locally to a decrease in the salinity of the coastal waters.

\subsection{Macrofaunal data - sampling and processing}

Temporal variability within the data differed between regions (Table 1), but all contributing datasets are largely constrained to recent data (starting from 1994). Though seasonal and interannual variation of $\mathrm{BP}_{\mathrm{c}}$ is omnipresent, generally spatial variation in $\mathrm{BP}_{\mathrm{c}}$ is significantly higher than temporal variation (see Supplementary material S1.2 and Gogina et al., 2017). The number of replicates and sieve size also deviated between sets, implying that comparisons between regions should be treated with caution.

Table 1 summarizes the different sampling strategies across the different regions. In DEBS, abundance and ash free dry weight biomass data were determined and averaged per station and standardised to the area of $1 \mathrm{~m}^{2}$. A separate grab sample was taken at each sampling event for the determination of sediment characteristics (grain size analysis by sieving or laser particle size analysis and organic content by loss on ignition). In DENS, wet mass (g) was determined in the laboratory, and AFDW (ash-free dry weight in g) was calculated using the conversion factor database of Brey (2001). When multiple replicates (mostly one to three) were taken per station, data was averaged per station prior to the analysis. In BENS, biomass was measured as wet weight. When data were missing, mean individual wet weight values were used for recalculation. Wet weight biomass was converted to AFDW (g) using species-specific conversion factors from the in-house list of the Leibniz Institute for Baltic Sea Research, Warnemünde, or, for taxa not in the list, values from Ricciardi and Bourget (1998). If no conversion factor was available for a taxon, the conversion factor of the next higher taxon level was used. As the BENS benthic datasets were collected by two institutes (ILVO and Marine Biology Research Group of Ghent University), over different sampling campaigns and by different people with a varying level of expertise in sample handling and identification, data were subjected to an intense quality control (Breine et al., 2018). In ENCH, the biomass of each taxon 
was determined in ash-free dry weight (AFDW, in g) per $0.5 \mathrm{~m}^{-2}$, by calculating a loss of weight of dry organisms after $6 \mathrm{~h}$ at $520^{\circ} \mathrm{C}$. Although we are aware that a $2 \mathrm{~mm}$ sieve may cause difference in the results, we used this available dataset considering that more than 95\% of the biomass (Ghertsos, 2002) and at least $83 \%$ of the biodiversity (Dethier and Berry, 2012) can be collected using such sieve mesh.

Table 1. Number of stations per sampling year, data set included in the study and related sampling strategy. DEBS = German part of the Baltic Sea; DENS = German part of the North Sea; BENS = Belgian part of the North Sea; ENCH = Eastern English Channel. Data sources: Leibniz Institute for Baltic Sea Research (DEBS), Alfred Wegener Institute Helmholtz Centre for Polar and Marine Research (DENS), ILVO and Marine Biology Research Group of Ghent University (BENS) and Ifremer (ENCH).

\begin{tabular}{|c|c|c|c|c|c|}
\hline & & DEBS & DENS & BENS & ENCH \\
\hline \multirow{23}{*}{ 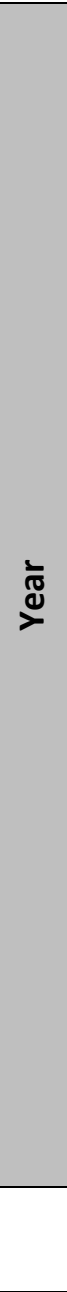 } & 1994 & & & 45 & \\
\hline & 1995 & & & 4 & \\
\hline & 1996 & & & 7 & \\
\hline & 1997 & & 42 & 88 & \\
\hline & 1998 & & 5 & 49 & \\
\hline & 1999 & 70 & 44 & 120 & \\
\hline & 2000 & 72 & 214 & 72 & \\
\hline & 2001 & 51 & 144 & 18 & \\
\hline & 2002 & 119 & 110 & 71 & \\
\hline & 2003 & 75 & 88 & 12 & \\
\hline & 2004 & 118 & 42 & 105 & \\
\hline & 2005 & 81 & 63 & 36 & \\
\hline & 2006 & 78 & 113 & 223 & 85 \\
\hline & 2007 & 128 & 15 & 192 & 8 \\
\hline & 2008 & 10 & & 285 & \\
\hline & 2009 & 162 & & 293 & \\
\hline & 2010 & 167 & & 309 & \\
\hline & 2011 & 54 & 28 & 173 & \\
\hline & 2012 & 102 & 56 & 114 & \\
\hline & 2013 & 168 & 36 & & \\
\hline & 2014 & 153 & 59 & & \\
\hline & 2015 & 26 & & & \\
\hline & $\begin{array}{c}\text { Total } \\
\text { (incl. measured median grain size) }\end{array}$ & $\begin{array}{c}1634 \\
(1115)\end{array}$ & $\begin{array}{l}1059 \\
(830)\end{array}$ & $\begin{array}{c}2216 \\
(1739)\end{array}$ & $\begin{array}{c}93 \\
(93)\end{array}$ \\
\hline \multirow{2}{*}{ 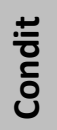 } & Range of median sediment grain size, $\mu \mathrm{m}$ & $6-4356$ & $28-4000$ & $12-770$ & $160-920$ \\
\hline & Range of depth, $m$ & $4.9-49.5$ & $9.6-67.9$ & $0-38.6$ & $7.0-53.5$ \\
\hline
\end{tabular}




\begin{tabular}{|c|c|c|c|c|c|}
\hline & Range of salinity & $5.7-30.2$ & $27.6-35.0$ & 34.3-34.7 & $34.2-34.7$ \\
\hline \multirow{4}{*}{ 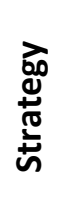 } & Number of replicates per station & 3 & 3 & 1 & 2 \\
\hline & Area sampled, $\mathrm{m}^{2}$ & 0.1 & 0.1 & 0.1 & 0.25 \\
\hline & Main sampling gear (grab type) & Van Veen & Van Veen & Van Veen & Hamon $^{a}$ \\
\hline & Sieve size, $\mathrm{mm}$ & 1 & 1 & 1 & 2 \\
\hline
\end{tabular}

\section{3. $\mathrm{BP}_{\mathrm{c}}$ calculation}

Bioturbation potential, used as proxy for benthic ecosystem functioning, was calculated (for each sampling event over the time spans covered by each data set) following the approach by Solan et al. (2004) with modifications described in Gogina et al. (2018):

$$
\mathrm{BP}_{\mathrm{c}}=\sum_{\mathrm{i}=1}^{\mathrm{n}} \mathrm{BP}_{\mathrm{pi}} \text {, where } \mathrm{BP}_{\mathrm{pi}}=\left(\mathrm{B}_{\mathrm{i}} / \mathrm{A}_{\mathrm{i}}\right)^{0.5} * \mathrm{~A}_{\mathrm{i}} * \mathrm{M}_{\mathrm{i}} * \mathrm{R}_{\mathrm{i}}
$$

where for taxon $i B_{i}$ is biomass (in ash-free dry weight AFDW $\mathrm{g} \mathrm{m}^{-2}$ ) and $A_{\mathrm{i}}$ is abundance (in ind. $\mathrm{m}^{-2}$ ) at each sample. $\mathrm{M}_{\mathrm{i}}$, mobility, and $\mathrm{R}_{\mathrm{i}}$, sediment reworking, are categorical scores assigned to each taxon based on ecological knowledge $\left(\mathrm{M}_{\mathrm{i}}: 1\right.$ - living in a fixed tube, 2 - limited movement, 3 - slow, free movement through the sediment, 4 - free three dimensional movement via burrow system; $R_{\mathrm{i}}: 1$ epifauna that bioturbate at the sediment-water interface, 2 - surficial modifiers, 3 - upward and downward conveyors, 4 - biodiffusors, 5 - regenerators that excavate holes, transferring sediment at depth to the surface). The revised scores used for each taxon included in the analysis in each of the four regions (and thus the corresponding taxa lists) can be found in the Supplementary material S2. Values for species population bioturbation potential, $\mathrm{BP}_{\mathrm{pi}}$, summed across all taxa in a sample gives an estimate of community-level bioturbation potential, $\mathrm{BP}_{\mathrm{c}}$. The original $\mathrm{BP}_{\mathrm{c}}$ equation (Solan et al., 2004) was adjusted by (i) using AFDW (instead of wet weight) biomass for the calculation, as it is often considered a better proxy for ecosystem functioning (e.g. Eklöf et al., 2017; Renz et al., 2018), and by (ii) totally excluding sedentary epifaunal species not involved in sediment transport from the calculation (i.e. species that scored 1 at both $M_{i}$ and $R_{i}$ were considered to have zero contribution to particle displacement in sediments).

\subsection{Key species selection criteria}

Key bioturbators were determined based on their contribution (i) to the cumulative total sum of $\mathrm{BP}_{\mathrm{c}}$ across all stations in each region and (ii) to each unique station BP $_{c}$ (similar to Gogina et al., 2017; Wrede et al., 2017). In DEBS overall 315 taxa contributed to bioturbation at 1634 sampling stations. 37 key species were 
selected using the criteria of (i) at least $0.1 \%$ contribution to the cumulative total sum of $\mathrm{BP}_{\mathrm{c}}$ across all stations or (ii) over $60 \%$ contribution to $\mathrm{BP}_{\mathrm{c}}$ at a unique station and being recorded for at least 40 stations. In DENS, 33 of the 479 taxa recorded at 1059 stations contributed to (i) at least $0.6 \%$ of total sum of $\mathrm{BP}_{\mathrm{c}}$ for all stations or (ii) over $50 \%$ at unique stations, and were found at more than 10 stations and were therefore selected as key species. For BENS 47 of 329 taxa recorded at 2216 stations were selected as key species using the criteria of contributing to (i) at least $0.5 \%$ of total sum of $\mathrm{BP}_{\mathrm{c}}$ or (ii) over $50 \%$ of $\mathrm{BP}_{\mathrm{c}}$ at unique stations and displaying at least 25 occurrences. In ENCH, 32 of 418 taxa recorded at 93 stations were selected as key species using the criteria of (i) at least $0.7 \%$ of total sum of $\mathrm{BP}_{\mathrm{c}}$ for all stations or (ii) over $50 \%$ at unique station. The reasoning behind certain numerical deviations in selection criteria used across different regions was the intention to keep the number of selected key species per area relatively limited (below 50, feasible for calculation and processing/operability). Relevant for management perspectives, unlike in most studies here we highlight species important in terms of their contributions to bioturbation potential, i.e. functional contributions rather than biomass or abundance dominance.

To examine if functionally important species differ from those dominating the biomass we have also compared the top 10 species as computed by $\mathrm{BP}_{\mathrm{c}}$ within and across regions relative to those computed from AFDW biomass.

\subsection{Sediment classification}

In order to harmonize sediment data, classification according to Wentworth (1922) was used for sampling events where median grain size data was available. The sediment classes (SedType) considered were: mud (M) $<63 \mu \mathrm{m}$, fine sand (FS) $63-250 \mu \mathrm{m}$, medium sand (MS) $250-500 \mu \mathrm{m}$, coarse sediment (CS) $\geq 500 \mu \mathrm{m}$ (see the map in Supplementary material S1.1).

\subsection{Abiotic predictors layers}

A combination of physical, chemical, and biological components has a direct influence on the integrity of species and its habitats, thereby limiting the distribution of assemblages and its functional indicators (Reiss et al., 2015). To account for changes in abiotic drivers, for each of the 4 regions, we have collated available full-coverage environmental layers that were assumed relevant for ecological and physiological constrains and used these layers as predictors for spatial distribution modelling of $\mathrm{BP}_{\mathrm{pi}}$ and $\mathrm{BP}_{\mathrm{c}}$. The sets for each region differed in number of predictor layers, origin, quality and resolution (Supplementary material S3). 
General details on predictors for DEBS can be found in Gogina et al. (2017): sediment median grain size and bathymetry were obtained from Tauber (2012a) and Tauber (2012b); modelled euphotic depth and bottom detritus averaged over 2000 to 2010 - from Friedland et al. (2012) and Schernewski et al. (2015); porosity was estimated according to Endler et al. (2015); modelled near-bottom mean summer temperature, salinity (mean and standard deviation, SD), bottom shear stress, mean bottom currents velocity, oxygen concentration, number of anoxic days and concentration of suspended particulate matter (SPM), covering the period of 2001-2015, were based on Klingbeil et al. (2014) and Gräwe et al. (2015); layers on substrate fine fraction smaller than $63 \mu \mathrm{m}$, total organic content (TOC), N, P and mobile P (Leipe et al., 2017) were obtained from the Baltic Sea Atlas (http://bio-50.io-warnemuende.de/secos).

For the DENS layers for sediment median grain size, sorting parameter and mud fraction $(<63 \mu \mathrm{m})$ were obtained from point data originated from the Marine Environmental Data Base (MUDAB). Average and maximum bottom shear stress from currents and waves data was available for February 2006 (see e.g. Stanev et al. 2008). For the interpolation of median grain size and sorting inverse distance weighting method was used, whereas for mud the Natural-Neighbour method was applied. Water depth layer was obtained from Schlüter and Jerosch (2009). Temperature and salinity data were derived by the Estuarine Transport Model (Stips et al., 2004).

For the BENS, median grain size layer is obtained from Verfaillie at al. (2006) and Van Lancker et al. (2007), bathymetry and silt-clay sediment fraction layers are described in Van Lancker et al. (2007), details on Belgian Bathymetric Position Index (BPI, measure of location's position and elevation in relation to the overall landscape) can be found in Verfaillie at al. (2009), data on Suspended Particulate Matter (SPM) was obtained using the algorithm described in Nechad et al. (2009; 2010). Layers on tidal current and wave energy and light at seabed were obtained from EMODnet Seabed Habitats portal (http://www.emodnet.eu/seabed-habitats).

Details on predictor layers for ENCH, including bathymetry, bed shear stress, SPM, chlorophyll a and Particulate Organic Carbon (POC), sediment type, waves, Bathymetric Position Index (BPIbel) can be found in Foveau et al. (2017). Data on light at seabed and currents induced average kinetic energy (ke $\mathrm{m}^{-2}$ ) at 1 $\mathrm{m}$ above the seabed were obtained from EMODnet. Near-bottom temperature and salinity (30 years average) refer to Núñez-Riboni and Akimova (2015).

\subsection{Statistical analyses}

To visualise the variation in relative contributions of taxa to $\mathrm{BP}_{\mathrm{c}}$ on various sediment types and between regions we used non-metric multidimensional scaling (nMDS) superimposed by the results of the group 
averaged Hierarchical Cluster analysis based on Bray-Curtis similarities. To test differences in the distribution of $\mathrm{BP}_{\mathrm{c}}$ across sediment types (four levels, fixed factor) and regions (four levels, random factor) we have used two-way non-parametric permutational analysis of variance PERMANOVA (McArdle and Anderson, 2001; PRIMER 7 with PERMANOVA add-on), including the interaction between sediment type (SedType) and region. Unless stated otherwise, significance level of statistical tests was set to $p<0.05$. In case of significance of the interaction term, pair-wise comparison was performed among SedType $\mathrm{x}$ region. PERMANOVA can be used to do univariate ANOVA based on permutations, thus avoiding the normality assumption, and is suitable for unbalanced data and heterogeneous dispersions among groups (Anderson, 2017).

PERMANOVA can be used to achieve partitioning for any additive model, but it is not particularly too sensitive to the differences in covariance structure, i.e. it does not care about the direction, but only about differences in dispersion (Anderson, 2017). Therefore, we have also assessed the trends of $\mathrm{BP}_{\mathrm{c}}$ changes within each region along the gradients in median grain size and diversity (species richness). In particular, to check the overall relationship between $\mathrm{BP}_{\mathrm{c}}$, sediment properties (median grain size) and biodiversity (species richness), also accounting for the possible regional effects and covariance with salinity and depth we have fitted a linear regression in $R$ ( $R$ Core Team, 2013). Subsequently, we have calculated the relative importance of each predictor in the fitted linear regression using the $\operatorname{Img}$ metric $\left(R^{2}\right.$ partitioned by averaging over orders) and package 'relaimpo' (Groemping, 2006). Kendall partial correlations were also checked prior to the analysis, using R package 'ppcor' (Kim, 2015) (Supplementary material S3).

For each region, we have also calculated the value of functional redundancy, defined as the difference between species diversity and Rao's quadratic entropy based on the functional dissimilarity (de Bello et al., 2007), based on abundance and bioturbation traits, i.e. mobility and reworking scores.

\subsection{Modelling approaches and estimates of predictive accuracy}

There are several ways to obtain full coverage maps for $\mathrm{BP}_{\mathrm{c}}$. To test methods appropriate for different applications and evaluate differences in results across methods and regions, in this study we have used three of them. We applied a Random Forest machine learning algorithm (Breiman, 2001) that comprises an ensemble of randomly constructed decision trees, using the R package "RandomForest" (RF, Liaw and Wiener, 2002; R Core Team, 2013). Separately for each region, we employed two modelling approaches: i) where community bioturbation potential $\mathrm{BP}_{\mathrm{c}}$ was initially the response variable (later referred to as "direct-BP ${ }_{c}$ " approach), and ii) where a separate model (and map) was derived for bioturbation potential $\mathrm{BP}_{\mathrm{p}}$ of each key species in the region as response variables, and resulting $\mathrm{BP}_{\mathrm{p}}$ estimates were subsequently 
summed together to derive an estimate of $\mathrm{BP}_{\mathrm{c}}$ distribution (later referred to as "species-resolved" approach, see also Gogina et al., 2017). We have also generated $\mathrm{BP}_{\mathrm{c}}$ maps using simple spatial interpolation by the natural neighbour method. The disadvantage of the last method relative to the proposed two modelling approaches is that fine-scale spatial differences between sampling locations are usually blurred, unless sampling density is sufficiently high (i.e. simple spatial interpolation methods are limited in including the variation of distribution driven by fine-scale habitat changes, see e.g. Franklin and Miller, 2010).

$\mathrm{BP}_{\mathrm{c}}$ and $\mathrm{BP}_{\mathrm{p}}$ values were $\log 10(\mathrm{x}+1)$ transformed prior entering the Random Forest models. We set the number of tree to 500 and we conducted a sensitivity analysis for the nodesize, i.e. the number of variables to be tested at each node, setting it from 1 to 5 , and subsequently taking the best performing model (based on highest $\%$ of variance explained).

Prediction of $\mathrm{BP}_{\mathrm{p}}$ for key species was based on the zero-inflated two-step procedure (Savage et al., 2015). First, presence/absence of considered species was predicted for each cell using binary classification RF. Second, only non-zero reference data was utilized to train a continuous RF regression model. The final region-wide prediction for each $\mathrm{BP}_{\mathrm{p}}$ was produced by combining the binary classification map with a continuous map: zero values were assigned to any cell predicted as absence; for cells that were identified as presence in the first step, the values from the second-step continuous prediction were assigned.

To estimate predictive accuracy of each modelling approach and compare them we used the nonparametric Kendall's $\tau$ rank correlation between $\mathrm{BP}_{\mathrm{c}}$ values based on observed macrofauna data and those resulted from Random Forest models. Modelling results were also compared with the results of natural neighbour spatial interpolation driven only by the input samples. This interpolation finds the closest subset of input samples to a query point and applies weights to them based on proportionate areas to interpolate a value. For the ENCH region, a comparatively low sample size (93 stations) was available. This raised the concern that the continuous models would provide poor predictive accuracy (e.g. negative \% of variance explained, indicating that it is better to simply predict any sample as equal to grand mean than using the given model) for species having lower frequency of occurrence. The "\% of variance explained" value was higher when the zero-inflation step was omitted. However, comparison of model results with observed data showed that the employment of the zero-inflated two-step method produced an overall more accurate prediction results. For the example for Galathea intermedia, Kendall's $\tau$ correlation between observed and predicted $\mathrm{BP}_{\mathrm{p}}$ values were 0.85 and 0.52 with and without zero-inflation step, 
respectively. In case of BENS all RF modelling and spatial interpolation processing was additionally done on $\mathrm{BP}_{\mathrm{c}}$ values aggregated per $1 \mathrm{~km}$ grid cell in order to level out temporal fluctuations.

We have grouped all predictors into nine larger categories according to the parameters they describe (sediment properties, food availability, oxygen conditions, salinity, exposure to currents (that can also be referred to as oceanographic stress), light conditions, temperature, depth, and human pressure, see Supplementary material S3) as the predictor layers differed between regions, to allow cross-comparisons of environmental drivers across regions. Subsequently, the importance of categories of environmental predictors in explaining the spatial distribution of $\mathrm{BP}_{\mathrm{c}}$ in the final models derived for each region was compared based on the values of the \%IncMSE (the increase in mean squared error of predictions as a result of variable $\mathrm{j}$ being permuted, i.e. values randomly shuffled, estimated with the out-of-crossvalidation), its corresponding maximum value per category, and its rank within all the predictors used in the final model per region.

\subsection{Simplified application example}

Regionally-derived $\mathrm{BP}_{\mathrm{c}}$ maps for each area can be converted to benthic ecosystem functioning maps, applicable for management purposes, as $\mathrm{BP}_{\mathrm{c}}$ may serve as proxy for estimates of spatial distribution of geochemical fluxes and nutrient cycling (Snelgrove et al., 2014; Gogina et al., 2018).

To illustrate the possible application of our proposed models we have estimated the spatial distribution of denitrification rates as function of $\mathrm{BP}_{\mathrm{c}}$ in the $\mathrm{BENS}$ region based on the significant regression reported in Braeckman et al. (2014): Denitrification $=0.68+0.004 * \mathrm{BP}_{\mathrm{c}}-3.00 \mathrm{e}^{-07 *} \mathrm{BP}_{\mathrm{c}}{ }^{2}$. It is important to note that in Braeckman et al. (2014) WW biomass was used to calculate $\mathrm{BP}_{\mathrm{c}}$. To solve this for our (simplified qualitative rather than quantitative) example, we applied the linear regression to convert AFDW-based $\mathrm{BP}_{\mathrm{c}}$ to $\mathrm{WW}$-based $\mathrm{BP}_{\mathrm{c}}$. If the resulting estimates were negative (unphysical) they were set to zero, as was suggested by Braeckman et al. (2014).

As the "species-resolved" modelling approach used here provides the information resolved to key species $\left(B P_{p}\right)$ level, the possible further application for it is testing the scenarios for key species loss or gain, i.e. an assessment of impact expected for ecosystem functioning when these species are subjected to anthropogenic pressures. For this purpose, we have removed the contributions of 14 randomly selected key taxa ( $30 \%$ of the contributing taxa) from $\mathrm{BP}_{\mathrm{c}}$ estimates by the "species-resolved" approach to assess the possible functional effect of structural biodiversity loss. 


\section{Results}

\subsection{Key species}

The summed $\mathrm{BP}_{\mathrm{p}}$ for the selected species was responsible for over $90 \%$ of total $\mathrm{BP}_{\mathrm{c}}$ in DEBS and $\mathrm{BENS}, 87 \%$ in DENS and slightly over 73\% in ENCH (Supplementary material S4). Top five species contributing most for each sediment type (mud, fine, medium or coarse sand) in each region are listed in Table 2.

Generally, some dominant (here and below in this section - dominant in terms of the contribution to $\mathrm{BP}_{\mathrm{c}}$ ) species were shared by all considered sediment types in the particular regions (such as Hediste diversicolor in DEBS or Echinocardium cordatum in both DENS and in ENCH). Concurrently, several taxa (including $E$. cordatum, Branchiostoma lanceolatum, Ensis leei or Nephtys spp.) appeared through several regions with some shift between the sediment types. For instance according to nMDS and Hierarchical Cluster analysis on relative $\mathrm{BP}_{\mathrm{p}}$, top contributors for coarse sand in $\mathrm{ENCH}$ were closer to medium and coarse sands in the DENS than to taxa listed for finer sediments of ENCH (see Figure 1). In all four regions the highest contribution of five top-most bioturbating taxa was found in fine sands.

In the DEBS, Hediste diversicolor had the overall highest contributions to total $\mathrm{BP}_{\mathrm{c}}$ in mud, medium and coarse sands (with respective contributions declining from 23 to $15 \%$ ). It was also listed $3^{\text {rd }}$ for fine sand, preceded by Arctica islandica and Peringia ulvae, with three species together sharing over $32 \%$ of total contribution in fine sands. In medium sand $H$. diversicolor and $A$. islandica accounted for $39 \%$ total $\mathrm{BP}_{\mathrm{c}}$. All shortlisted species were either surficial modifiers or biodiffusors. Limecola balthica, Diastylis rathkei and Nephtys ciliata were shortlisted only for muddy stations; Tubificoides benedii and Tubificidae - only for coarse sands.

For muddy sediments of DENS, Amphiura filiformis, Nucula nitidosa and Nephtys hombergii together accounted for nearly $67 \%$ of total $\mathrm{BP}_{\mathrm{c}}$. Amphiura filiformis also had marked contribution in fine and medium sands. Echinocardium cordatum was most dominant in fine sands, but was shortlisted for all 4 sediment types and responsible for over $25 \%$ of total $\mathrm{BP}_{\mathrm{c}}$ in the region. Branchiostoma lanceolatum had the highest contribution in medium and coarse sands; Ophelia borealis and Nephtys caeca were also listed among top 5 for these two sediment types. Most of listed species were attributed to slowly free moving biodiffusors; Ensis leei (listed only for mud) was a single shortlisted surficial modifier.

At the muddy stations of BENS Abra alba, Notomastus latericeus and Anthozoa together accounted for over $50 \%$ of total $\mathrm{BP}_{\mathrm{c}}$, whereas $E$. leei and $A$. alba shared over $40 \%$ of total contribution in fine sands. In contrast to the DENS, Nephtys cirrosa had the highest contribution in medium and coarse sands; $E$. 
cordatum was listed only for those two sediment types. For medium sand stations it was followed by $E$. leei, for coarse sands - Branchiostoma lanceolatum and O. borealis had higher contributions.

In the ENCH again E. cordatum was the most important bioturbator at fine sand stations (as well as among all stations included in the analysis), followed by $N$. cirrosa and O. borealis. N. cirrosa and Ophiothrix fragilis contributed most in medium sands. B. lanceolatum, listed fifth for medium sands, was on the first place in coarse sands.

Remarkably, there are species that are within the top 5 across all sediment types within a region, e.g. Hediste diversicolor in DEBS, as well as species that are in within the top 5 for a specific sediment type across regions, e.g. B. lanceolatum and $O$. borealis in coarse sand across 3 of the four regions. This can help to point out species that might be important to protect or manage, but which are often neglected in management plans. 
Table 2. Top five key taxa listed per sediment type per each region. The values for species contribution (in \%) to the total $\mathrm{BP}_{\mathrm{c}}$ at all stations considered for each region indirectly indicates the dominance of the particular sediment type in the area. Also the percent of total $\mathrm{BP}_{\mathrm{c}}$ at all stations covering specific sediment type, and mobility $(M)$ and reworking $(R)$ scores attributed to each taxon (indicated by the first and the second digit, correspondingly; for meaning of scores refer to section 2.3) are indicated.

\begin{tabular}{|c|c|c|c|c|c|c|c|c|c|c|c|c|c|c|c|c|}
\hline \multirow{2}{*}{$\begin{array}{l}\text { Sediment } \\
\text { type }\end{array}$} & \multicolumn{4}{|c|}{ DEBS } & \multicolumn{4}{|l|}{ DENS } & \multicolumn{4}{|l|}{ BENS } & \multicolumn{4}{|l|}{$\mathrm{ENCH}$} \\
\hline & Taxa & $\begin{array}{l}\bar{\pi} \\
0 \\
+ \\
0 \\
0 \\
0\end{array}$ & 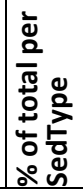 & 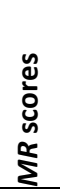 & Taxa & $\begin{array}{l}\bar{\pi} \\
0 \\
+ \\
4 \\
0 \\
0\end{array}$ & 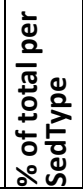 & 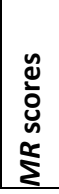 & Taxa & 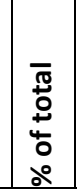 & 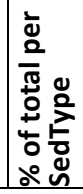 & 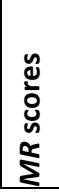 & Taxa & 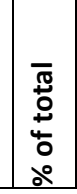 & 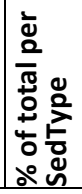 & 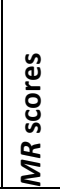 \\
\hline \multirow{6}{*}{$\begin{array}{l}\text { Mud } \\
\text { M }\end{array}$} & Hediste diversicolor & 2.1 & 23.4 & 44 & Amphiura filiformis & 2.2 & 48.9 & 34 & Abra alba & 0.05 & 23.5 & 22 & & & & \\
\hline & Arctica islandica & 1.8 & 1.7 & 22 & Nucula nitidosa & 0.6 & 13.1 & 32 & Notomastus latericeus & 0.04 & 19.0 & 23 & & & & \\
\hline & Nephtys ciliata & 0.8 & 0.2 & 34 & Nephtys hombergii & 0.2 & 4.9 & 34 & Anthozoa & 0.02 & 11.7 & 22 & & & & \\
\hline & Diastylis rathkei & 0.7 & 0.9 & 32 & Echinocardium cordatum & 0.2 & 4.9 & 34 & Eunereis longissima & 0.02 & 9.8 & 44 & & & & \\
\hline & Limecola balthica & 0.7 & 2.7 & 22 & Ensis leei & 0.1 & 3.0 & 22 & Cirratulidae & 0.02 & 7.8 & 22 & & & & \\
\hline & Sum & 6.1 & 28.9 & & Sum & 3.3 & 74.7 & & Sum & 0.2 & 71.8 & & & & & \\
\hline \multirow{6}{*}{\begin{tabular}{|l} 
Fine \\
sand \\
FS
\end{tabular}} & Arctica islandica & 4.0 & 12.3 & 22 & Echinocardium cordatum & 25.4 & 31.4 & 34 & Ensis leei & 24.2 & 33.9 & 22 & E. cordatum & 9.3 & 27.6 & 34 \\
\hline & Peringia ulvae & 3.8 & 11.6 & 32 & Amphiura filiformis & 18.1 & 22.4 & 34 & Abra alba & 5.4 & 7.6 & 22 & Nephtys cirrosa & 4.1 & 12.2 & 34 \\
\hline & Hediste diversicolor & 2.7 & 8.3 & 44 & Nemertea & 3.7 & 4.5 & 34 & Lanice conchilega & 4.5 & 6.3 & 13 & Ophelia borealis & 1.8 & 5.4 & 34 \\
\hline & Mya arenaria & 2.4 & 7.3 & 22 & Spiophanes bombyx & 2.3 & 2.9 & 13 & Owenia fusiformis & 4.4 & 6.1 & 12 & Ophiothrix fragilis & 1.4 & 4.2 & 22 \\
\hline & Scoloplos armiger & 2.4 & 7.3 & 34 & Nephtys hombergii & 2.1 & 2.6 & 34 & Nephtys hombergii & 3.3 & 4.6 & 34 & Scoloplos armiger & 0.9 & 2.6 & 34 \\
\hline & Sum & 15.3 & 46.8 & & Sum & 51.6 & 63.7 & & Sum & 41.8 & 58.5 & & Sum & 17.6 & 52.0 & \\
\hline \multirow{6}{*}{$\begin{array}{l}\text { Medium } \\
\text { sand } \\
\text { MS }\end{array}$} & Hediste diversicolor & 2.4 & 21.3 & 44 & Branchiostoma lanceolatum & 1.2 & 15.5 & 34 & Nephtys cirrosa & 3.0 & 22.6 & 34 & Nephtys cirrosa & 4.2 & 9.8 & 34 \\
\hline & Peringia ulvae & 1.4 & 1.7 & 32 & Amphiura filiformis & 0.9 & 11.6 & 34 & Echinocardium cordatum & 1.9 & 14.3 & 34 & Ophiothrix fragilis & 3.3 & 7.7 & 22 \\
\hline & Astarte borealis & 1.2 & 1.1 & 22 & Echinocardium cordatum & 0.8 & 10.5 & 34 & Ensis leei & 1.3 & 9.5 & 22 & Echinocyamus pusillus & 2.4 & 5.7 & 32 \\
\hline & Arctica islandica & 1.1 & 17.7 & 22 & Ophelia borealis & 0.7 & 9.2 & 34 & Ophelia borealis & 0.5 & 3.8 & 34 & Ophelia borealis & 2.3 & 5.5 & 34 \\
\hline & Scoloplos armiger & 0.9 & 5.5 & 34 & Nephtys caeca & 0.3 & 3.7 & 34 & Anthozoa & 0.5 & 3.5 & 22 & B. lanceolatum & 1.9 & 4.4 & 34 \\
\hline & Sum & 7.0 & 47.3 & & Sum & 4.1 & 50.5 & & Sum & 7.1 & 53.8 & & Sum & 14.1 & 33.2 & \\
\hline \multirow{6}{*}{$\begin{array}{l}\text { Coarse sand } \\
\text { CS }\end{array}$} & Hediste diversicolor & 1.8 & 15.4 & 44 & Branchiostoma lanceolatum & 3.4 & 53.2 & 34 & Nephtys cirrosa & 0.1 & 28.6 & 34 & B. lanceolatum & 3.7 & 8.7 & 34 \\
\hline & Tubificoides benedii & 0.5 & 2.8 & 34 & Echinocardium cordatum & 0.3 & 4.5 & 34 & Ophelia borealis & 0.04 & 9.7 & 34 & Glycymeris glycymeris & 1.8 & 4.3 & 22 \\
\hline & Tubificidae & 0.5 & 2.4 & 34 & Ophelia borealis & 0.3 & 4.2 & 34 & B. lanceolatum & 0.03 & 6.2 & 34 & E. cordatum & 1.1 & 2.5 & 34 \\
\hline & Peringia ulvae & 0.4 & 8.7 & 32 & Orbinia & 0.2 & 3.2 & 34 & Echinocardium cordatum & 0.02 & 5.5 & 34 & Glycera lapidum & 1.0 & 2.4 & 34 \\
\hline & Astarte borealis & 0.4 & 7.3 & 22 & Nephtys caeca & 0.2 & 2.6 & 34 & Oligochaeta & 0.02 & 4.1 & 34 & Glycinde nordmanni & 0.8 & 1.9 & 34 \\
\hline & Sum & 3.6 & 36.6 & & Sum & 4.3 & 67.8 & & Sum & 0.2 & 54.1 & & Sum & 8.5 & 19.9 & \\
\hline
\end{tabular}




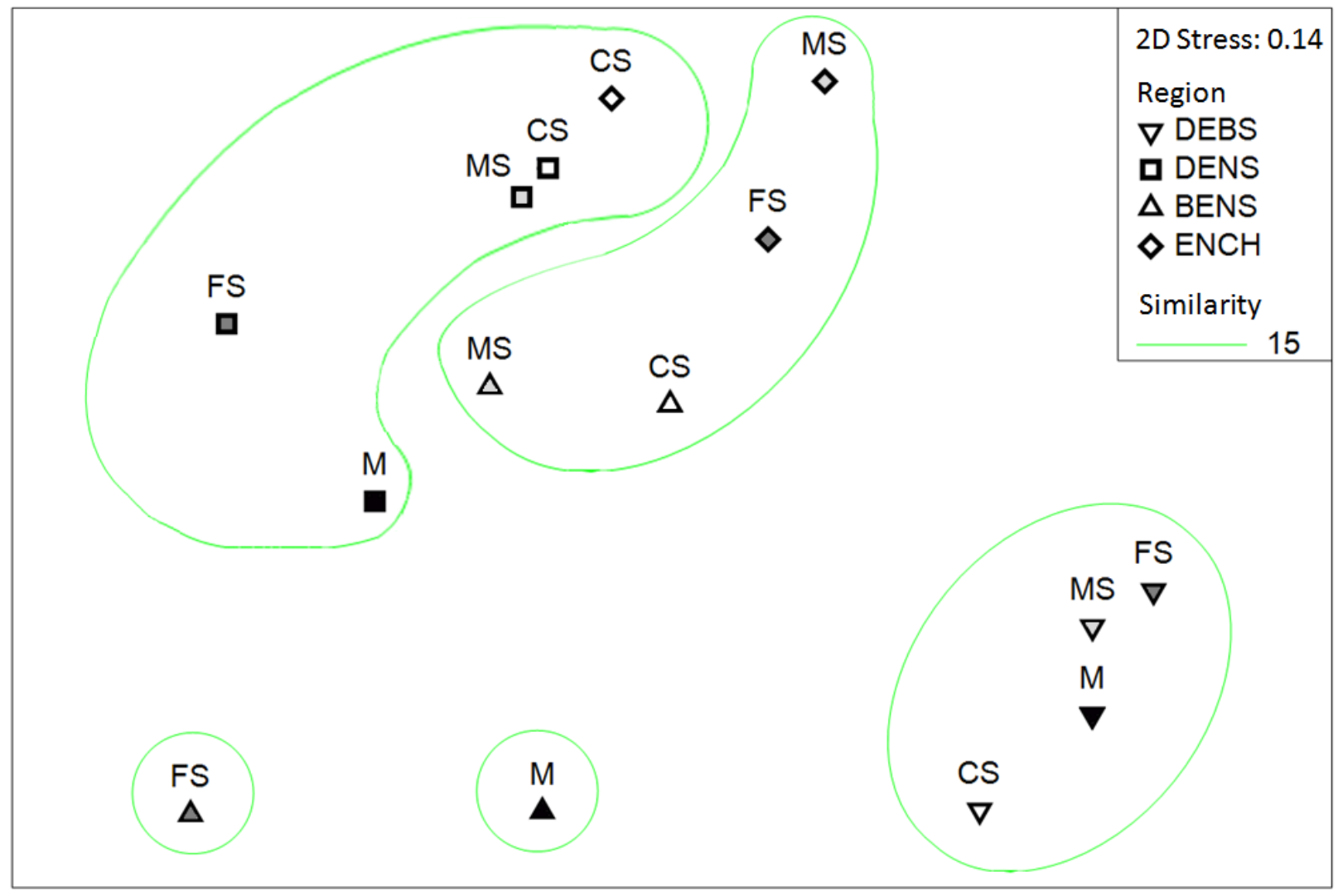

Fig. 1. Non-metric multidimensional scaling ordination plot of Bray-Curtis similarities based on squareroot transformed species contributions to $\mathrm{BP}_{\mathrm{c}}$ (relative $\mathrm{BP}_{\mathrm{pi}}$ ) in 4 sediment types at each region. Labels (and colour of the symbols) indicate sediment type (see section 2.5 for abbreviations), shapes of the symbols indicate different regions. Contours indicate the $15 \%$ Bray-Curtis similarities cut-off according to Hierarchical Cluster analysis (group average) to visually highlight differences.

The comparison of top 10 species as computed by $\mathrm{BP}_{\mathrm{c}}$ within (see Supplementary material S1.3) and across regions (see Table 3) relative to those computed from AFDW biomass showed that: (i) there are regional differences, (ii) 4 species appeared in both lists and comprised $>20 \%$ of both total $\mathrm{BP}_{\mathrm{c}}$ and total AFDW biomass across the 4 regions, and (iii) there is also a mismatch between those that are functionally important and those that dominate biomass, for the reason that biomass as a metric does not account for what species with that biomass do. 
Table 3. Top 10 key taxa contributing to total $\mathrm{BP}_{\mathrm{c}}$ and AFDW biomass across all 4 regions. Taxa indicated in bold fond appear in both lists (i.e. dominate both $\mathrm{BP}_{\mathrm{c}}$ and $\mathrm{AFDW}$ biomass).

\begin{tabular}{|l|r|l|r|}
\hline Taxa & \% of total BP $_{\mathbf{c}}$ & Taxa & \% of total AFDW biomass \\
\hline Echinocardium cordatum & $11.4 \%$ & Echinocardium cordatum & $12.6 \%$ \\
\hline Ensis leei & $6.6 \%$ & Arctica islandica & $10.5 \%$ \\
\hline Amphiura filiformis & $5.3 \%$ & Ensis leei & $8.5 \%$ \\
\hline Nephtys cirrosa & $4.5 \%$ & Lanice conchilega & $6.3 \%$ \\
\hline Hediste diversicolor & $2.8 \%$ & Arcopagia crassa & $5.8 \%$ \\
\hline Branchiostoma lanceolatum & $2.7 \%$ & Mytilus edulis & $3.9 \%$ \\
\hline Scoloplos armiger & $2.7 \%$ & Amphiura filiformis & $3.2 \%$ \\
\hline Limecola balthica & $2.5 \%$ & Laevicardium crassum & $3.2 \%$ \\
\hline Peringia ulvae & $2.4 \%$ & Glycymeris glycymeris & $2.3 \%$ \\
\hline Arctica islandica & $2.2 \%$ & Mya arenaria & $2.2 \%$ \\
\hline \multicolumn{1}{|c|}{ Sum } & $43.1 \%$ & & Sum \\
\hline
\end{tabular}

\subsection{Differences in bioturbation potential between sediment types and regions}

The effect of sediment type on $\mathrm{BP}_{\mathrm{c}}$ was regionally dependent (two-way PERMANOVA Region $\mathrm{x}$ SedType interaction term: $\mathrm{P}($ perm $)<0.05$; see Supplementary material S5).

Results of pairwise tests (Fig. 2A) indicated that similar magnitudes of the $\mathrm{BP}_{\mathrm{c}}$ occur in DEBS and DENS for coarse and fine sand, and between BENS and ENCH for coarse sand (Fig. 2A). In DEBS no significant difference in $\mathrm{BP}_{\mathrm{c}}$ values was found between fine, medium and coarse sand, where $\mathrm{BP}_{\mathrm{c}}$ was higher than in muddy sediments. In DENS BP ${ }_{c}$ values in medium sand were significantly lower than records for mud, fine or coarse sand. In the BENS highest variability and therewith highest overlap was observed for all sediment type subsets, hence, no significant difference in $\mathrm{BP}_{\mathrm{c}}$ values between the different sediment types were found. $\mathrm{BP}_{\mathrm{c}}$ values for the $\mathrm{ENCH}$ were significantly lower in fine and medium sand compared to those in coarse sand.

Generally, lowest median $\mathrm{BP}_{\mathrm{c}}$ values were recorded in $\mathrm{ENCH}$, and $\mathrm{BP}_{\mathrm{c}}$ in $\mathrm{BENS}$ was lower than in DEBS and DENS as well (Fig. 2B). Concurrently, there was a slight increase of calculated median values of functional redundancy observed from DEBS to ENCH (Supplementary material S5). 
A

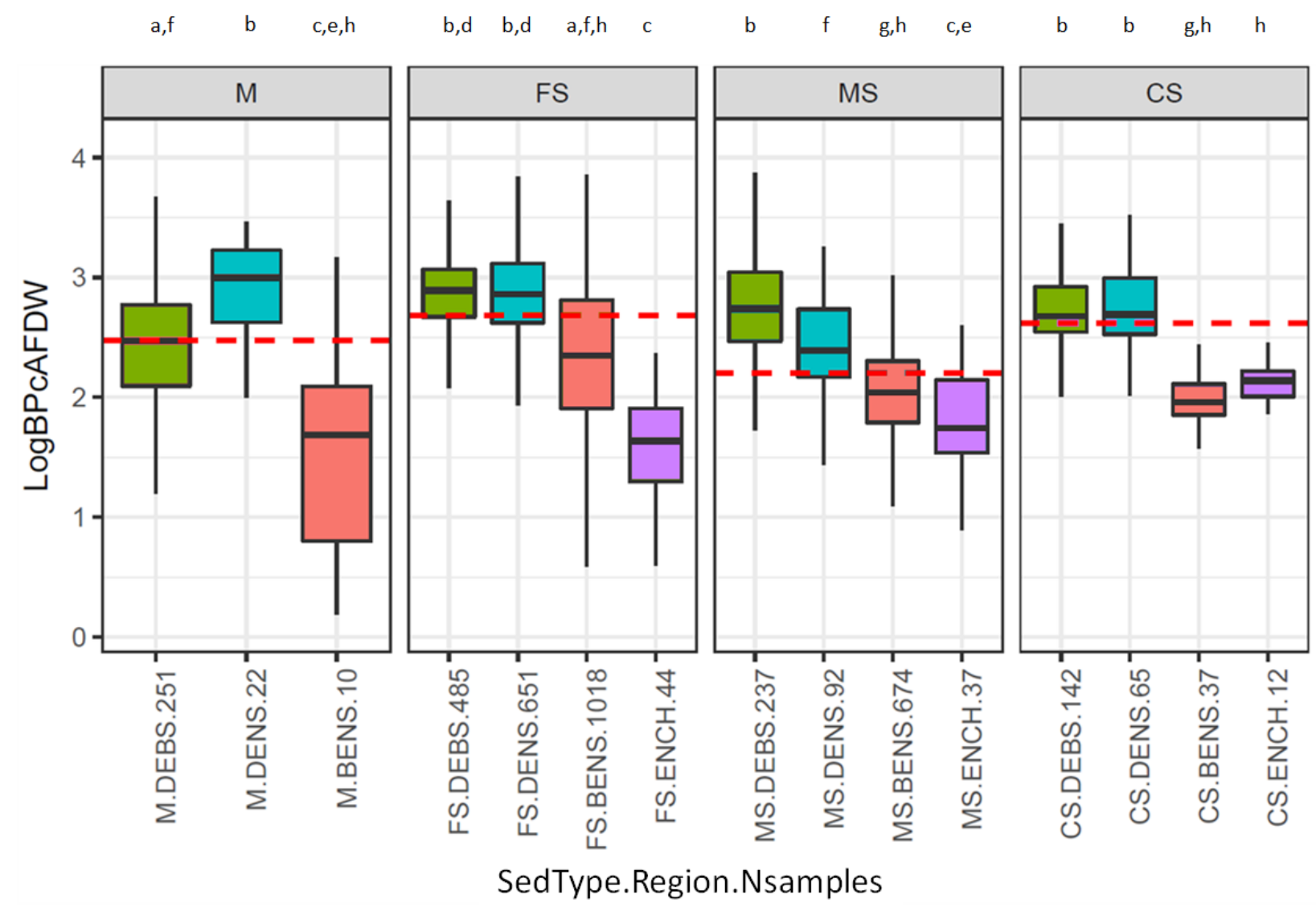

B

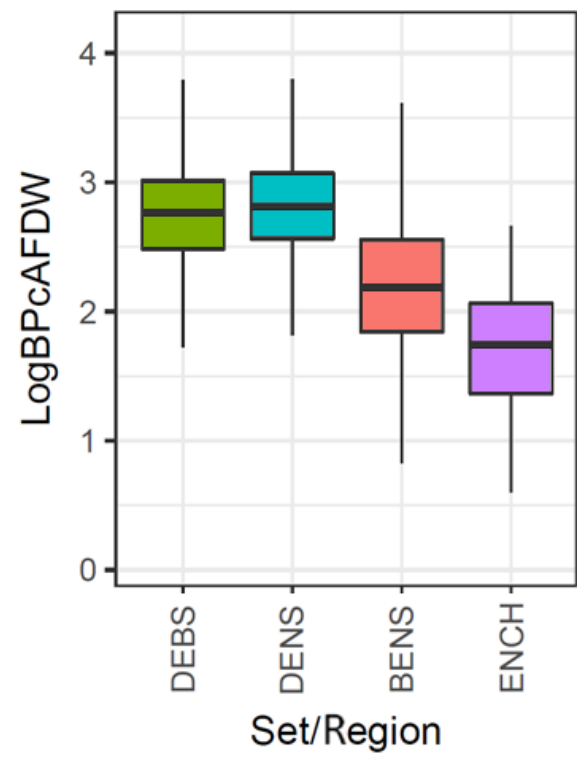

Fig. 2. Boxplots showing $(A)$ regional differences in $B P_{c}$ between different sediment types $(M, F S, M S$ and CS are mud, fine sand, medium sand and coarse sediment, respectively, see Section 2.5; colour-coded are different regions). Numbers in the labels indicate the number of stations included in each subset. Dashed 
red line indicates the median $\mathrm{BP}_{\mathrm{c}}$ level per sediment type. Subsets sharing the same letter above the plots are not significantly different (based on pairwise tests within PERMANOVA). (B) Differences in $\mathrm{BP}_{\mathrm{c}}$ between different regions. Whiskers span from the bottom $5 \%$ to the upper $95 \%$, boxes span from $25 \%$ to $75 \%$.

\subsection{Spatial distribution}

Results of modelling and interpolation of spatial distribution of $\mathrm{BP}_{\mathrm{c}}$ are shown in Figure 3, for DEBS, DENS, BENS and ENCH, respectively. Generally, Kendall's $\tau$ values (calculated to evaluate method performance) were highest for the simple spatial interpolation approach for all the regions, confirming its closest association with observations. Furthermore, Kendall's $\tau$ values for RF modelling using $\mathrm{BP}_{\mathrm{c}}$ as response ("direct-BP" approach; Fig. 3A) were always higher than those corresponding to the "species-resolved" modelling approach based on the summation of $\mathrm{BP}_{\mathrm{p}}{ }^{\prime} \mathrm{s}$ for key species (Fig. 3B).

In our "direct- $\mathrm{BP}_{\mathrm{c}}$ " modelling approach using $\mathrm{BP}_{\mathrm{c}}$ as response variable in RF models, the final models explained $51.37 \%$ of the total variance of $\mathrm{BP}_{\mathrm{c}}$ in the DEBS, $37.21 \%$ in the DENS, $36.9 \%$ in the BENS and $28.22 \%$ in the ENCH region (Supplementary material S4). The resulting maps for each region are shown in Figs. 3A. Maps resulting from the "species-resolved" approach predicted by an ensemble of RF models are shown in Figs. 3B. The variance explained by species-specific models $\mathrm{BP}_{\mathrm{p}}$ models for key species ranged greatly, from $69.6 \%$ for both Bathyporeia pilosa in DEBS and Amphiura filiformis in DENS to only noise fitted (negative value of variance explained by continuous model) for many key taxa like Nephasoma minutum in the ENCH (see Supplementary material S4). 

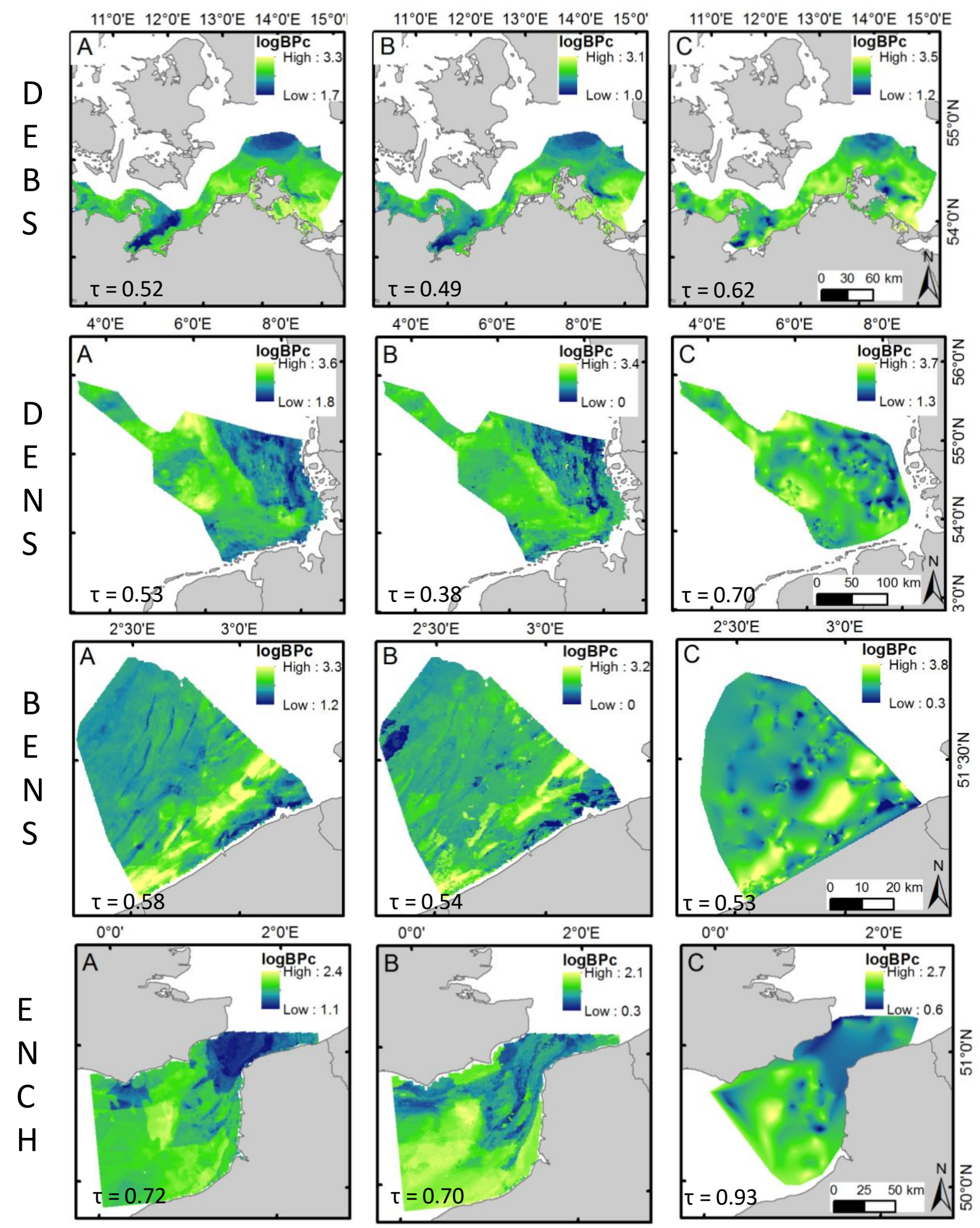

Fig. 3. Predicted surfaces of spatial distribution of $B P_{c}$ (log-transformed values) in the different regions (A) direct $\mathrm{RF}$ modelling of $\mathrm{BP}_{\mathrm{c}}$ as response variable ("direct- $\mathrm{BP}_{\mathrm{c}}$ ” approach), (B) summation of $\mathrm{BP}_{\mathrm{p}}$ 's predicted by an ensemble of RF models for key species ("species-resolved" approach), and (C) natural neighbour 
interpolation results (iii approach; Projection: WGS_1989_UTM_Zone_32N). Kendall's $\tau$ with observed values are reported on each figure $(p<0.05)$.

Based on the "direct- $\mathrm{BP}_{\mathrm{c}}$ " modelling approach, $\mathrm{BP}_{\mathrm{c}}$ values in DEBS were mainly linked to sediment properties (i.e. median grain size and porosity), followed by food availability (sediment organic content and SPM), oxygen conditions and salinity (Table 4, Supplementary material S3). In DENS sediment properties, followed by exposure to currents (bottom shear stress due to waves), bottom temperature and human pressure (namely trawling frequency) affected $\mathrm{BP}_{\mathrm{c}}$ values most. In BENS bathymetry, sediment properties (\% of silt and clay in sediments) and current energy were the most important drivers. In ENCH these were current energy, bottom temperature and salinity.

The average rank of most important predictors for the "species-resolved" modelling approach differed from the main drivers listed above for the "direct- $\mathrm{BP}_{\mathrm{c}}$ " approach. This was expected, as for the entire assembly of species-specific $\mathrm{BP}_{\mathrm{p}}$ models, the most important predictors can only be extracted by averaging the ranks of predictors ranks for each species. Thus it reflects an average combination of environmental preferences and sensitivity of selected key taxa listed for each region (Supplementary material S2 and S3). In DEBS these drivers were depth, salinity and light conditions. In DENS, sediment properties (median grain size), exposure to currents (kinetic energy at the bottom) and bottom temperature were most important in driving most of the species-specific $\mathrm{BP}_{\mathrm{p}}$ models. In BENS food availability (particular organic carbon and SPM), bottom salinity, temperature and depth were the most important predictors in a set of models predicting species-specific $\mathrm{BP}_{\mathrm{p}}$. In the $\mathrm{ENCH}$, again food availability (particular organic carbon), bottom temperature and salinity were often the most important predictors in the "species-resolved" approach. 
Table 4. The importance of different categories of environmental predictors in explaining the spatial

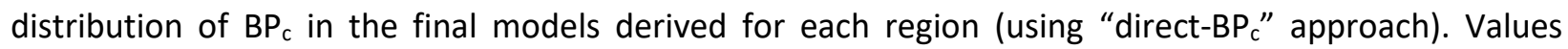
correspond to the maximum \%IncMSE per category. The colour intensity of each cell inversely corresponds to the rank of the group of predictors per regions (i.e. from most important category of predictors in dark red to least important in grey), whereas white cells indicate that predictors of the category were not available for the corresponding region.

\begin{tabular}{rcccc} 
& DEBS & , DENS & BENS & ENCH \\
\hline sediment_properties - & 30.4 & 19.6 & 37.3 & 8.4 \\
food_availability - & 29.3 & 13.6 & 35.2 & \\
oxygen_conditions - & 26.4 & & & \\
salinity - & 25 & 11.4 & 30.4 & 16.9 \\
\hline exposure_to_currents - & 24.9 & 14.4 & 36.7 & 24.4 \\
light - & 24.1 & 2.6 & 34 & \\
temperature - & 22.8 & 13.9 & 34.4 & 18.9 \\
depth - & 21 & 10 & 39.4 & 12 \\
human - & & 14 & & \\
\hline
\end{tabular}

\subsection{Effects of sediment grain size and biodiversity}

When treating data from all regions together, $\mathrm{BP}_{\mathrm{c}}$ was stronger, and positively, associated with biodiversity (species richness) than with median sediment grain size (Fig. 4 and Supplementary Material $\mathrm{S} 5)$. Linear regression analysis suggests that $\mathrm{BP}_{\mathrm{c}}$ value in $\mathrm{DEBS}$ were higher than in other regions, for stations having similar species richness and median grain size (and also controlling for weak effects of salinity and depth). Associations of $\mathrm{BP}_{\mathrm{c}}$ with median grain size vary in the direction between regions, but were overall weak (Supplementary Material S5). Relative importance of factors driving the overall patterns of $\mathrm{BP}_{\mathrm{c}}$ assessed using Img metric (Table 5) was highest for species richness and region, followed by their interaction and salinity, whereas the effects of depth and median grain size were marginal.

A large variation of $\mathrm{BP}_{\mathrm{c}}$ occurs along sediments similar in grain size (Fig. 4A). Difference in fitted regionspecific trend lines highlights that the relationship between $\mathrm{BP}_{\mathrm{c}}$ and sediment type differs between 
regions. Moreover, a large range of $\mathrm{BP}_{\mathrm{c}}$ occurs even along the low species richness values (Fig. 4B), suggesting that provisioning of high bioturbation activity is possible also under low diversity but high abundance and biomass, respectively.
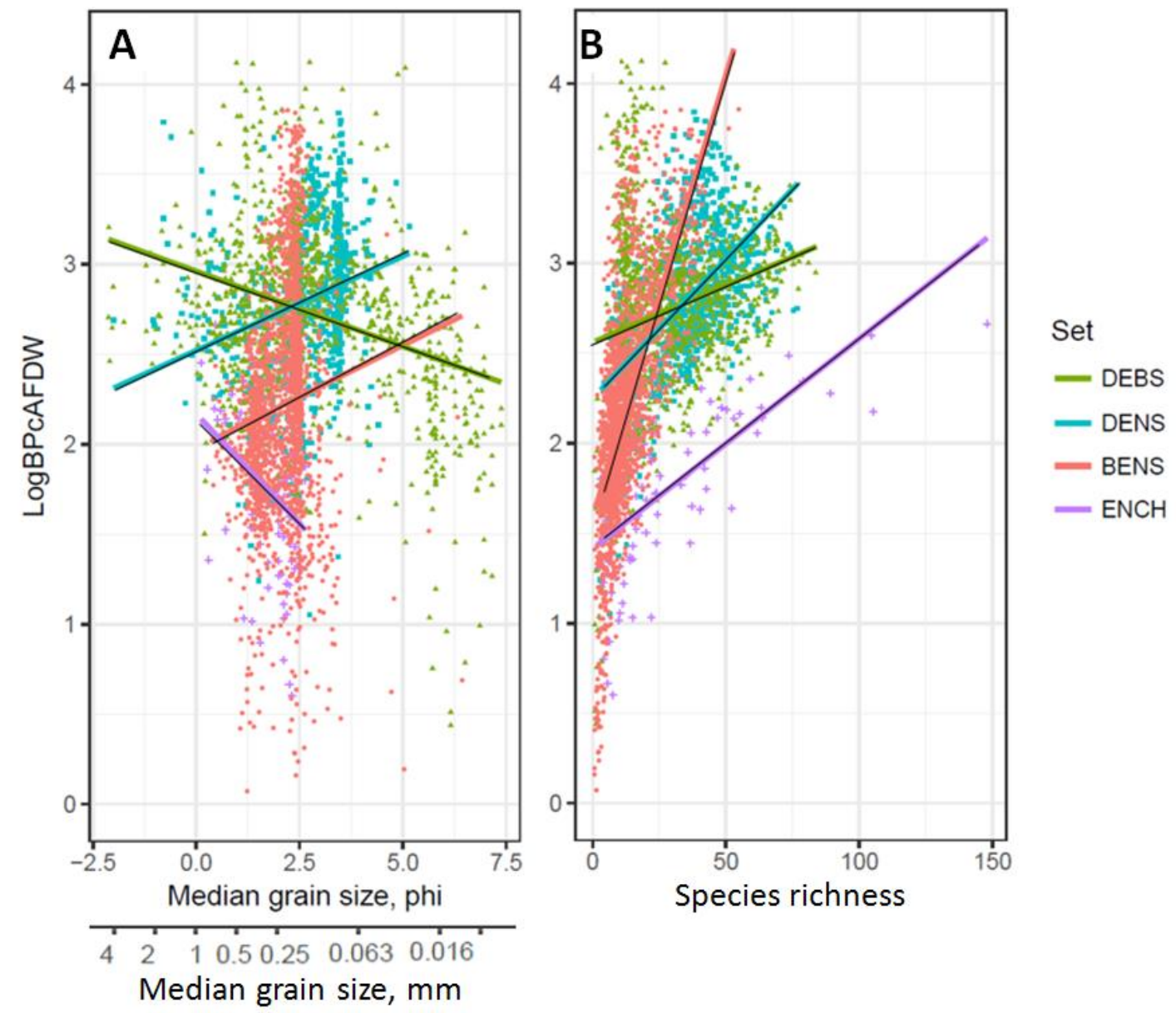

Fig. 4. Scatter plot of $\mathrm{BP}_{\mathrm{c}}$ (log-transformed values) in each region against (A) median grain size and (B) species richness. The simple region-specific trend lines are fitted by generalized linear models to illustrate general patterns (see also Supplementary Material S5.4). Note that the slope should not be compared between regions as the sieve size and number of replicates deviated between regions. 
Table 5. Relative importance of (groups of) regressors based on the Img metric, including interactions.

\begin{tabular}{|llc|}
\hline Regressor/group & Img & Img normalized \\
\hline Number of species & 0.216 & 0.390 \\
Median grain size, mm & 0.004 & 0.006 \\
Region (group of 3 regressors) & 0.159 & 0.288 \\
Depth, $\mathrm{m}$ & 0.025 & 0.045 \\
Salinity & 0.032 & 0.058 \\
Median grain size : Region & 0.007 & 0.013 \\
Number of species : Region & 0.110 & 0.200 \\
\hline
\end{tabular}

\subsection{Application example - simplified estimate of species loss effect for denitrification in BENS}

The resulting estimated distribution of denitrification in $\mathrm{BENS}$, calculated as function of $\mathrm{BP}_{\mathrm{c}}$, is shown in Fig. 5. The removed species accounted together for $16 \%$ of $\mathrm{BP}_{\mathrm{c}}$ in the area (with Nephtys hombergii and Scoloplos armiger having the highest contributions to $\mathrm{BP}_{\mathrm{c}}$ of 7 and $5 \%$, respectively).

The resulting predictions suggested highest rates of denitrification occurring in the fine sandy sediments south off the Flemish Banks and in the central and western coastal area. The "species-resolved" approach generally underestimates denitrification relative to the results obtained using "direct-BP ${ }_{c}$ " approach (Fig. $5 A-5 C)$.

Overall lowest denitrification rates occur further offshore in the permeable sediments in the northern parts of the area and in the muddy sediments near the Western Scheldt estuary, where also the highest (over $50 \%$ ) relative reduction of denitrification is predicted by the "species-resolved" approach under the tested theoretical scenario of biodiversity loss (Fig. 5D-5E). 


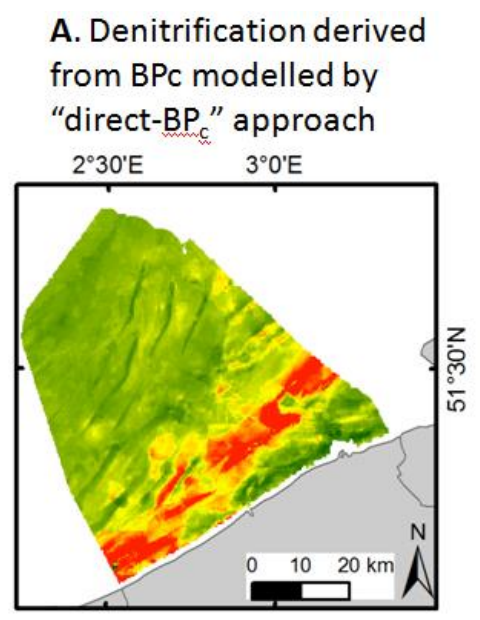

B. Denitrification derived from BPc modelled by "species-resolved" approach
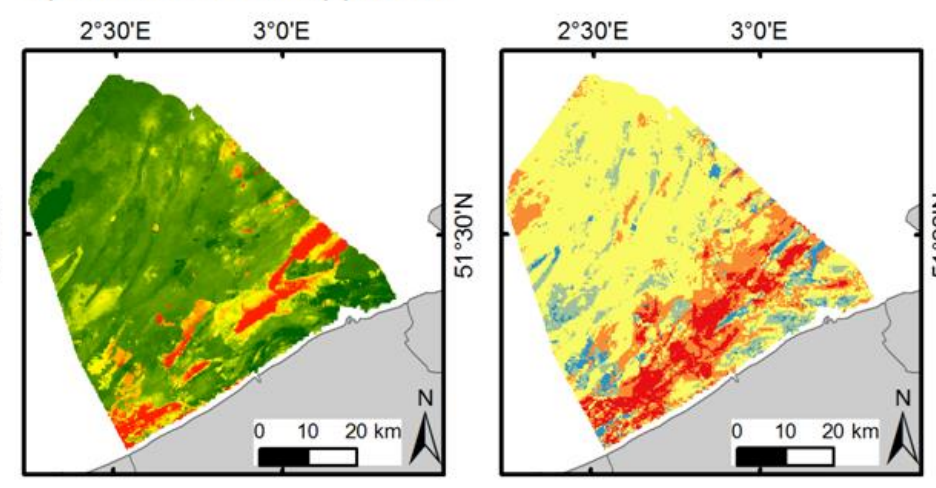

denitrification $\mathrm{mmol} \mathrm{N} \mathrm{m}^{-2} \mathrm{~d}^{-1}$ High : 14.01

Low : 0 z్ difference in $\mathrm{mmol} \mathrm{N} \mathrm{m}^{-2} \mathrm{~d}^{-1}$ $-10.58--4.69$ $-4.68--2.67$ $-2.66--1.13$ $-1.12-0$ $0.01-14.01$

\section{E. Change (D-B) in \%}

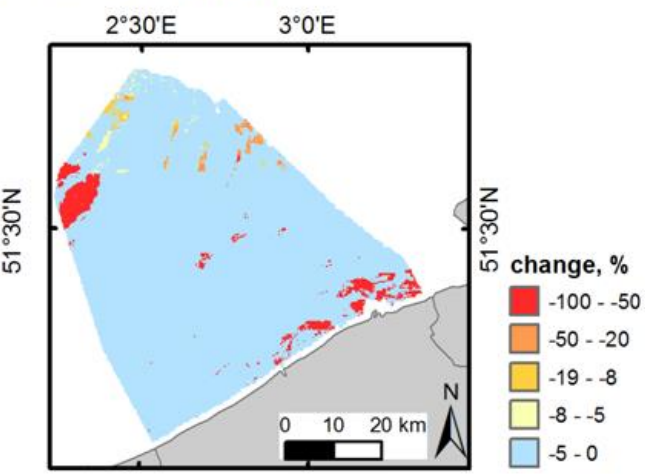

Fig. 5. Estimated denitrification in $\mathrm{mmol} \mathrm{N} \mathrm{m}^{-2} \mathrm{~d}^{-1}$ in BENS calculated (based on the findings of Braeckman et al. 2014) as function of $\mathrm{BP}_{\mathrm{c}}(\mathrm{A})$ modelled by "direct-BP" approach, (B) modelled by second approach accounting for all key species, and (D) using "species-resolved" approach after the loss of 14 random species. The deviations of the denitrification estimates based on $\mathrm{BP}_{\mathrm{c}}$ derived by two modelling approaches (C) and the potential changes of denitrification rates caused by species loss (E).

\section{Discussion}

Marine ecosystems are experiencing rapid and pervasive changes in biodiversity and species composition. Understanding the consequences of these changes for ecosystem functioning and assessing biodiversityecosystem functioning relationships is critical to effectively manage these systems (Gamfeldt et al., 2015; Strong et al., 2015; Birchenough et al., 2015; Zeppilli et al., 2016). Instead of focussing on species restoration only, sustainable management should also focus on ecological functions that support ecosystem services important for humanity. Bioturbation is one important ecological function of marine 
benthos that is often associated with enhanced nutrient cycling in and from sediments (Gamfeldt et al. 2015). Therefore, studies addressing large scale bioturbation patterns in macrobenthic communities are urgently needed in order to assess dedicated processes and functions across these areas. In this study we identified for the first time the region and sediment-specific key species contributing to $\mathrm{BP}_{\mathrm{c}}$, over 4 distinctive regions along the European Shelf. We analysed regional patterns and drivers by modelling the spatial distribution of $\mathrm{BP}_{\mathrm{c}}$, and generated $\mathrm{BP}_{\mathrm{c}}$ maps that can highlight hot-spots of benthic ecosystem functioning, which should be considered in the context of conservation goals and marine management.

\subsection{Key species}

In each region we observed a similar pattern of a few species contributing strongly to bioturbation, whereas other species contributed very little (Supplementary material S1.3, Supplementary material S4). Interestingly, very few key species occurred across multiple regions. However, if they were found in multiple regions, their contribution to $\mathrm{BP}_{\mathrm{c}}$ was high in one region and small in the other. This suggests the overall importance of functional redundancy in communities (see Supplementary material S5.3 and the discussion below).

Similar to the results of Solan et al. (2012) for the North Sea, the contributions of key functionally important species varied tremendously between locations and regions; in this study, specifically, substantial differences were also revealed depending on selection procedure, i.e. based on AFDW biomass or contribution to $\mathrm{BP}_{\mathrm{c}}$. Across all 4 regions, there were four species that appear to be particularly important both functionally and in terms of biomass - Echinocardium cordatum, Ensis leei, Amphiura filiformis, Arctica islandica - where the first three species are mainly present in the North Sea, while the last one is important in the Baltic Sea. Species that were selected both via $\mathrm{BP}_{\mathrm{c}}$ and $A F D W$ reflect the fact that $\mathrm{BP}_{\mathrm{pi}}$ is indeed partly influenced by biomass. However, there was also a mismatch between functionally important species (in terms of $\mathrm{BP}_{\mathrm{c}}$ ) and those that dominated biomass, reflecting the importance of differences in species behaviour (Hale et al., 2014).

\subsection{General and regional patterns}

Bioturbation may be thought as the result of reworking of sediment by the different species as they dig into the sediment for feeding or hiding from predators. Therefore, bioturbation is a combination of local properties (i.e., more related with the ecological features of the species causing it) and large-scale properties (i.e., related with broader environmental conditions; Gray and Elliott, 2009). The comparison between the regions in our study allowed us to highlight the gradient from areas fully driven by local-scale conditions (DEBS) to areas fully driven by broad-scale environmental conditions (e.g., ENCH). For instance 
in DEBS bioturbation was mostly driven by sediment type and food availability, whereas in ENCH bioturbation was mostly driven by exposure, temperature and salinity. Regions between these two extremes, i.e. DENS and BENS had mixed conditions of drivers acting at local spatial scale (e.g., sediment type) and those acting at broad spatial scale (e.g., exposure; for definition of spatial scales see Pittman, 2017). We think that the slight trend of increase in calculated values of functional redundancy (Supplementary material S5.3) observed from the DEBS to the ENCH matches the trend of conditions from the local-scale (in DEBS) to broad-scale (in ENCH). In fact, drivers acting at local scale may support a higher heterogeneity of habitat and communities and therefore a wider range of functional redundancy. In turn, drivers acting at broad scales may support a narrower span of functional redundancy.

The remarkable decrease of $\mathrm{BP}_{\mathrm{c}}$ from low-saline and species poor Baltic Sea towards the southern part of the North Sea (Fig. 2) appeal for more regional investigations (but see Gogina et al., 2017, Wrede et al., 2017). This phenomenon perhaps is also inversely related to functional redundancy (Supplementary material S5.3), that is expected to be lowest in the species poor areas where few (sometimes large) species with high dominance (Supplementary material S5.2) can potentially translate in increased levels of ecosystem functioning (as for example in case of Arctica islandica, Mya arenaria and Hediste diversicolor in DEBS). Conceivably, this reflects an effect of the mathematical formulation of $\mathrm{BP}_{\mathrm{c}}$ (see Section 2.3) that results in higher inflation when a large number of lower scaled values is summed together compared to the sum of a lower number of high values. More precisely, the scaling factor 0.5 , used in $\mathrm{BP}_{\mathrm{c}}$ in this study, puts relatively more weight on species with low body mass and high abundance (like Peringia ulvae), which might in turn cause a potential bias towards Baltic Sea specimens that tend to be smaller (Supplementary material S1.3 and S5.2). Both mobility and reworking mode scores weighted by abundance tend to be higher in the Baltic Sea and decline towards ENCH (Table 2). Furthermore, the reduction of $\mathrm{BP}_{\mathrm{c}}$ index towards the lower latitudes within the investigated dataset must be sought in the reduction in biomass and abundance per area. Such pattern can be observed in previous works that studied the global distribution of those metrics of biodiversity, e.g. Wei et al. (2010). The distribution of abundance and biomass values compared between regions (see boxplots in Supplementary material S5), suggest that both major community parameters are important in shaping the patterns of $\mathrm{BP}_{\mathrm{c}}$ (e.g. $\mathrm{BP}_{\mathrm{c}}$ differences between regions in coarse sand sediments rather mirror the variability in biomass, than in abundance). A further reason for decreasing $\mathrm{BP}_{\mathrm{c}}$ towards the south may rely on the expectation that conditions of higher food supply from the water column favour the presence of species which score lower in both motility and sediment reworking, causing a general reduction in $\mathrm{BP}_{\mathrm{c}}$. For example, Anthozoa as well as some other taxa that depend on food supply from the water column (e.g. Ensis), rather than on 
sedimentary food, are indicated as key species in BENS (see Table 2). To examine a relationship between $\mathrm{BP}_{\mathrm{c}}$ and primary production (used as proxy for food supply) we have compared our resulting $\mathrm{BP}_{\mathrm{c}}$ maps with primary production layers (averaged from February to October) published by Melin (2013). In contrast to findings of Meyer et al. (2019), we found significant negative correlation between $\mathrm{BP}_{\mathrm{c}}$ and primary production for the DENS region $(R=-0.53, p<0.001)$, though it was positive for BENS and DEBS $(R=0.52$ and $R=0.70$, respectively, $p<0.001)$, and not significant for $E N C H$.

\subsection{Potential environmental drivers of biogeographic patterns of $\mathrm{BP}_{\mathrm{c}}$}

It is important to account for differences in sediment habitat when assessing biogeographic patterns, as for example much of the functioning is undertaken by physical processes rather than biological processes in sand habitats, whilst the reverse is true in muddy sediments (Sciberras et al. 2017; Hale et al. 2017; Godbold et al. 2017). Accounting for spatial differences even at smaller scale of distinct seafloor morphologies was found crucial for improving management of goods and services delivered by marine ecosystems (Zeppilli et al., 2016).

Similar to previous findings, highest $\mathrm{BP}_{\mathrm{c}}$ values were associated with fine sand sediments in DENS and BENS (Meyer et al. 2019; Braeckman et al. 2014; Breine et al. 2018), whereas it was lowest in medium to coarse permeable sands in DENS and in very shallow muddy sediments in BENS. This observed weak negative trend of $\mathrm{BP}_{\mathrm{c}}$ with increasing median grain size in the German and Belgian parts of the North Sea could indicate that less species are adapted to the pressure of high exposure conditions (e.g. due to survival of only small and mobile species in highly dynamic areas).

Due to difference in conditions and settings across different benthic habitats of the four regions their formal comparison is challenging. For example, the environmental settings (e.g. with respect to organic matter loading, salinity) of muddy sediments in DEBS and those in the BENS are different and are expected to constrain slightly different communities. Key fine sand species in ENCH are partly corresponding to species in medium sands in BENS. The structural differences (composition, density, biomass and diversity) in communities are reflected in different magnitudes of estimated bioturbation potential and the relative importance of environmental drivers of $\mathrm{BP}_{\mathrm{c}}$ for each area (Table 4).

Food availability was an important driver of the biogeographic patterns in $\mathrm{BP}_{\mathrm{c}}$ in this study (see Table 4 and the discussion above). In the North Sea in general, biomass increases consistently in finer sediments and sediments with higher chlorophyll a content (Heip et al., 1992), but this is different in the Baltic Sea (Darr et al., 2014). In the DEBS in particular, also oxygen conditions and salinity were major drivers of the distribution of $\mathrm{BP}_{\mathrm{c}}$. Here hypoxia limits the distribution of species in the deeper bays with finer sediments, 
and a strong salinity gradient drives the overall biodiversity (Darr et al., 2014; Zettler et al., 2017). Hypoxia affects the activities of benthic animals leading to decreased bio-irrigation and bioturbation rates, which are eventually eliminated when benthic animals have disappeared as a result of oxygen stress (Middelburg and Levin, 2009), with major consequences for sediment biogeochemistry and species interactions (Belley et al. 2010; Van Colen et al. 2012; Giffiths et al. 2017; Calder-Potts et al. 2018).

Unlike causal predictors like temperature, salinity, or primary production, water depth may be considered an indirect proxy integrating several (potentially not included) predictor variables (Reiss et al., 2015), such as human pressures. The depth ranges considered were relatively comparable across the four regional datasets, with the exception of BENS region, where also very shallow locations were included in the dataset. This is probably the reason why it was among the most important predictors for the BENS region, although in other regions depth displayed less influence on the variability of $\mathrm{BP}_{\mathrm{c}}$.

In the $\mathrm{ENCH}$, current energy and temperature were among the most important predictors. Though we had no layer of fishing pressure available for this region, it is possible that the effect of high fishing pressure here is attenuated by the effects of hydrodynamics, with flatfish fisheries mostly associated with fine and medium sands (Hinz et al., 2006) and scallop fisheries - with coarse sand (Szostek et al., 2016). Particularly, strong fishing activity in this area can reduce or exclude the largest, generally fragile, species.

\subsection{Temporal variability and implications of changes}

The focus of our study is on the spatial patterns across regions, whereby temporal differences were beyond the scope of our analysis. This was justified by the fact that spatial variability of $\mathrm{BP}_{\mathrm{c}}$ in our data exceeded the temporal variation (see Supplementary material S1, as well as Gogina et al. 2017 for justification in DEBS). Also, long-term studies in DENS reported stable spatial distribution of four major communities (e.g. Kröncke et al., 2011), although some structural changes were observed within each of them. According to Boyé et al. (2019), benthic spatial beta diversity structure remained remarkably stable and temporal variability was of small extent to the south-west of ENCH (based on the 2008-2014 data from monitoring of benthic macrofauna across the Brittany).

On the other hand, further studies suggest that temporal variation on the long and short terms require more attention. Meyer et al. (2019) detected a steady increase in $\mathrm{BP}_{\mathrm{c}}$ across the south-eastern North Sea since 1986, with the exception of the central and northern Oysterground, where a significant drop in $\mathrm{BP}_{\mathrm{c}}$ was found. They also revealed a shift in dominance of functional groups within major communities up to 2010-2015 that was related to anthropogenic pressures (fishery, seabed degradation), increasing sea surface temperature, food limitation, and de-eutrophication. 
It is important to acknowledge that the replacement of one functional group by another could, but not necessarily, result in $\mathrm{BP}_{\mathrm{c}}$ changes (see also Thomsen et al., 2017 for insights on post-extinction compensatory responses). The introduction of Ensis leei, a relatively large, abundant and very active species, is a good example of a shift that could completely modify the $\mathrm{BP}_{\mathrm{c}}$ in the newly colonized areas. Moreover, considering the importance in the total $\mathrm{BP}_{\mathrm{c}}$ in the DENS and BENS and the massive mortalities this species can exhibit (e.g. Dannheim and Rumohr, 2012), high temporal variations in the $\mathrm{BP}_{\mathrm{c}}$ values following such events are not unlikely. This, and our results on the relationship between $\mathrm{BP}_{\mathrm{c}}$ and species diversity, are also largely consistent with the meta-analysis findings of Gamfeldt et al. (2015) that showed tendency of more diverse communities to enhance levels of ecosystem function relative to the average monocultures, but to have no or negative effect on functioning relative to the 'highest-performing' (i.e. key) species.

\subsection{Comparison and application of two modelling approaches}

Overall patterns resulting from two modelling approaches were similar (and generally close to patterns resulting from interpolation), justifying the usefulness of both approaches, depending on the application of the model results. The direct modelling of $\mathrm{BP}_{\mathrm{c}}$ was always closer to observations and interpolation approach (based on Kendall's $\tau$ estimates). Models derived by the "direct-BP" approach (i) can be recommended to produce maps identifying potential bioturbation hot spots, irrespective of species contributing to them. The "species-resolved" approach (ii) can provide a better solution when impact of specific taxa is questioned. It allows differentiating between species responsible for the occurrence of those hot spots in different areas of the region, reflecting the suitability of conditions for particular bioturbation agents, and testing the scenarios of change in their distribution. The natural neighbour interpolation approach (iii) in turn provides the results most seconded by the observed values (i.e. generates most evidence-based distribution maps comparing with both modelling approaches that rely on the assumptions of parameterised links of $\mathrm{BP}_{\mathrm{c}}$ to abiotic predictors). The obvious disadvantage of spatial interpolation, however, is the inability to predict and the lack of resolution in space between samples where observations are absent.

Our simplified application example helped to illustrate a potential application of the proposed models to quantify consequences of biodiversity changes for ecosystem functioning. This aspect was not the main focus of this study. Nevertheless, it raised some interesting points to consider in the discussion of this work. The resulting estimates showed that denitrification estimates mainly follow the distribution patterns in macrofauna, both in terms of diversity and $\mathrm{BP}_{\mathrm{c}}$. When comparing with models excluding 14 
species, the highest relative reductions in denitrification emerged in the areas with lowest initial denitrification rates (Fig. 5E). Those results, placed aside with BENS maps of $\mathrm{BP}_{\mathrm{c}}$ derived by two modelling approaches (Fig. 3, BENS A and B) suggest that those areas have remarkably low values of summed $\mathrm{BP}_{\mathrm{c}}$ determined by key functional species at the regional scale, though values determined by direct $\mathrm{BP}_{\mathrm{c}}$ approach are comparable with other areas of $\operatorname{low}_{-} \mathrm{BP}_{\mathrm{c}}$ in this region. This suggests different levels of biodiversity and evenness in these areas of the BENS, which are in turn related to different degrees of change in denitrification rates after biodiversity loss. On the other hand, this can also simply be a result of model artefact, and the issue requires further investigation that is beyond the scope of this paper. We can only note that the functionally most important species at the regional scale also dominate in biomass and abundance (see Supplementary material S1.3), but possibly in these particular areas (with lowest estimated initial denitrification rates) other species, that are generally rare on regional scale, could determine the maintenance of ecosystem properties. Wohlgemuth et al. (2016) found that the most dominant species exert a disproportionate influence on functioning at low levels of evenness. However, a system with many species of low dominance and high evenness, where species-specific contributions are low, can be more resistant to change when comparing to situations with only few dominant species. Due to higher functional redundancy associated with high evenness, i.e. low contribution scenario, the disappearance of a species will not strongly destabilize the functioning. We would like to note that the presented example was most simple and easy to implement. Alternatively, the denitrification estimate could be based on $\mathrm{BP}_{\mathrm{c}}$ based on original macrofauna data, interpolating values spatially using natural neighbour method, and subsequently repeating the exercise after removal of the species from the original dataset. Finally, it is important to highlight that this theoretical example works for regions where a close relationship is demonstrated between $\mathrm{BP}_{\mathrm{c}}$ and ecosystem functions, as demonstrated in Braeckman et al. (2014). However, this is not the case everywhere and potential limitations of the method are discussed below.

\subsection{Performance, flaws and limitations of $\mathrm{BP}_{\mathrm{c}}$ modelling}

There are several limitations associated with the models and $\mathrm{BP}_{\mathrm{c}}$ index itself, which are related to regional low sampling efforts, validation of the index by measurements and limited knowledge on species traits.

Low model performance of many species-specific models was indicated for ENCH. This can be partly explained by the low number of stations in the dataset. In random forests, negative variance explained is a clear warning that the model might be overfitting a lot of noise in the data, and the ensemble of trees 
fits little of the true patterns. However, similar general trends were found in the densely sampled BENS as well, suggesting that observed patterns for $\mathrm{ENCH}$ are realistic.

There is a clear level of uncertainty, which differed between models for the different key species in the "species-resolved" modelling approach (Supplementary material S4) and is further hindered after summation of the species-specific $\mathrm{BP}_{\mathrm{p}}$ results to calculate the $\mathrm{BP}_{\mathrm{c}}$ estimates. Presumably, model accuracy decreases with increasing number of key species, but precision increases. As such, the model result for BENS, where highest number of key species was considered, has the lowest accuracy. This consideration appeals for additional caution with regards to the results of our application example (Section 3.5).

Addressing the issue of the relation between $\mathrm{BP}_{\mathrm{c}}$ and benthic processes, there is still a need for more experiments simultaneously investigating benthic mineralisation processes and macrofaunal functional traits to permit a more formal validation. Databases that collect experimental data worldwide now start to emerge, and they could greatly help to validate the index in the future. One good example is the recent publication by Solan et al. (2019) covering bioturbation intensity, ventilation rate, and mixing depth measurements of marine sediments (though high temporal variability and low spatial coverage of measurements included hinder large-scale spatial assessments).

Our level of knowledge on traits is good for a limited number of species and traits, but more discursive for the others, leading to the accumulation of minor mistakes or imprecisions. We argue that due to large number of included species, straightforward selection of relatively well-known traits and modalities, and multiple quality checks of trait scores by regional experts (Supplementary material S2), our modelling approaches to produce full-coverage maps, estimating $\mathrm{BP}_{\mathrm{c}}$ values at a regional scale, are justified. Increased knowledge on species ecology and trait scores will indeed lead to changes in the absolute values of the modelled $\mathrm{BP}_{\mathrm{c}}$ scores, but we are confident that the geographical patterns and relation with environmental variables are accurately reflected by our methodology.

We aimed to infer general patterns, compare and explore the differences in distribution, key contributing species and possible drivers of $\mathrm{BP}_{\mathrm{c}}$ between the four regions. Common problems for such inter-regional comparisons are: 1 - inclusion of datasets unbalanced in size, covered period, species diversity and distribution of sediment types, that require a trade-off between data availability and consistency of analysis; 2 - due to high variability of species distribution occurring under similar conditions and limited sets of available predictors, low model accuracy for some species cannot be avoided.

\subsection{A word of caution: utility of $\mathrm{BP}_{\mathrm{c}}$ to reflect ecosystem functioning}


Several studies have validated the performance of $\mathrm{BP}_{\mathrm{c}}$ and similar indicators against measured bioturbation (e.g. Gogina et al., 2017; Queirós et al., 2015) and bioirrigation rates (e.g. Wrede et al., 2018), indicating that they are robust enough to be complementary, but are not an alternative to direct measurements (see e.g. Wohlgemuth et al., 2017). Importantly, such indicators are rather a proxy for functionally important ecosystem processes, and a combination of experimental and modelling work remains the most promising method to quantify the importance of ecosystem engineers on the biogeochemical functioning of aquatic ecosystems (Mermillod-Blondin, 2011). Furthermore, there is a need for more comprehensive descriptors to account for behavioural aspects affecting ecosystem functioning (Hale et al., 2014).

The general purpose of this paper was to give an indication of the relative role of bioturbation in generic terms. In this context, it is important to point out that $\mathrm{BP}_{\mathrm{c}}$ was developed to reflect particle reworking (Solan et al., 2004), and not for the purpose of linking it with ecosystem functioning per se. The metric can be useful in this way, but care needs to be taken for its appropriate use and resulting conclusions, as its utility depends on whether or not it fits the functional data (e.g. Kristensen et al., 2012; Queirós et al., 2015; Gogina et al., 2018). For instance, $B_{c}$ does not always fit the data on nutrient fluxes: in cases it does, one important explanation can again be that the index reflects a process (such as particle displacement) that substantially contributes to the transport process. In other areas where it does not, the contribution of fauna is not important, e.g. when mineralization processes in permeable sediments are constrained by advective currents (Mermillod-Blondin, 2011). Subsequent papers have added bioirrigation to the metric (Wrede et al., 2018; Renz et al., 2018), which may probably be more appropriate when considering many of the functions we care about, such as nutrient cycling. Spatially explicit fullcoverage layers of distribution of bioirrigation-based indices can be then obtained in a similar manner as was done here for $\mathrm{BP}_{\mathrm{c}}$. $\mathrm{BP}_{\mathrm{c}}$, as used in this paper, is more appropriate for mixing depths (Queirós et al., 2015) and sediment stability (Cozzoli et al., 2018).

Hence, and taking into account the regional variation reported here, $\mathrm{BP}_{\mathrm{c}}$ should not be applied widely across different systems and in relation with many functions, before more work is done to understand when and where the metric is appropriate, and what the mechanistic basis behind it is.

In a perfect world, there would be no need for the $\mathrm{BP}_{\mathrm{c}}$ metric, as we would have a value for per capita contributions for each species across a range of functions we are most interested in. However, we know very little about the functional role of individual species in terms of actual measurements. Our analysis of $\mathrm{BP}_{\mathrm{c}}$ highlighted focus species requiring special attention in the regions considered. $\mathrm{Yet}_{\mathrm{BP}}$ is reflecting 
only a summation of capacity based on coarse assumptions about species traits, biomass and density, whereas the actual contribution of individual species and organisms to processes in the real natural realm can by far not be resolved.

\section{Conclusions}

The executed multi-regional analysis allowed to identify regional differences in performance of macrofauna reflected by $\mathrm{BP}_{\mathrm{c}}$, which suggests that conservation and management strategies need to be region specific at scales less than, for example, the North Sea. Unlike most studies, we have highlighted species that appear to be important in terms of their functional contributions rather than biomass (or abundance) dominance. For many of these identified key species there are only few studies published yet. Full-coverage maps of $\mathrm{BP}_{\mathrm{c}}$ for each region were obtained, providing semi-quantitative information on functional aspects of macrofaunal communities and their major drivers. Both modelling algorithms provided satisfactorily results and predicted similar patterns of spatial distribution of $\mathrm{BP}_{\mathrm{c}}$; the usefulness of both approaches for different scientific questions and management applications was demonstrated. Analysis of available data suggested large variation of bioturbation potential, and occurrence of high bioturbation capacity even under low diversity. Our results further highlight the difference in importance of environmental drivers in the different regions (see Table 4), suggesting that same predictors cannot be used in different biogeographic areas. A number of shortcomings buried in the index formulation and modelling approaches invoke caution in use of acquired information. Coarse modelling exercises like this can be useful for providing a large-scale picture that level out multiple sources of fine-scale spatial and temporal variability to managers and decision makers. However, it is impossible to overemphasize the necessity of experimental measurements for validation purposed and provisioning us with mechanistic details to develop the whole ecosystem-level understanding, including biogeochemical cycles, and disentangle multiple main linkages, overseen so far, in order to improve predictability and achieve sustainable governance (Hofmann et al., 2016).

\section{Acknowledgements}

This publication was initiated and facilitated by the Benthos Ecology Working Group (BEWG), which is an expert group of the International Council for the Exploration of the Sea (ICES). MG was financed by German Federal Ministry for Education and Research KÜNO Project SECOS-Synthese (03F0738) and the 
BONUS ECOMAP project supported by BONUS (Art 185) at different stages of work on this manuscript. The BENS work is framed within the Face-it project (Functional biodiversity in a changing sedimentary environment: implications for biogeochemistry and food webs in a managerial setting), financed by BELSPO (BR/154/A1/Face-it). U.B. is a senior postdoctoral fellow at the Research Foundation - Flanders (FWO; Grant No. 1201720N).

\section{Supplementary material}

Supplementary material S1: Map with sampling stations and sediment type layer, temporal and spatial variability of $\mathrm{BP}_{\mathrm{c}}$, lists of top 10 key taxa contributing to total $\mathrm{BP}_{\mathrm{c}}$ and to total $\mathrm{AFDW}$

Supplementary material S2: Species lists with traits scores per region

Supplementary material S3: List of available abiotic predictors, predictor's importance, partial correlation Supplementary material S4: Model performance for $\mathrm{BP}_{\mathrm{c}}$ and key species

Supplementary material S5: PERMANOVA, boxplots for AFDW, abundance and species richness, Functional Redundancy

\section{References}

Anderson, M. J. 2017. Permutational Multivariate Analysis of Variance (PERMANOVA). In Wiley StatsRef: Statistics Reference Online: 1-15. doi.org/10.1002/9781118445112.stat07841

Aneiros, F., Moreira, J., and Troncoso, J. S. 2018. Temporal variation of polychaete assemblages and their bioturbation potential in subtidal sedimentary bottoms. Journal of Sea Research, 142: 66-78. doi: 10.1016/j.seares.2018.09.008.

Arndt, S., Lacroix, G., Gypens, N., Regnier, P., and Lancelot, C. 2011. Nutrient dynamic and phytoplankton development along an estuary-coastal zone continuum: A model study. Journal of Marine Systems, 84: 49-66.

Arntz, W.E. 1981. Zonation and dynamics of macrobenthos biomass in an areastressed by oxygen deficiency. In Stress Effects on Natural Ecosystems, pp. 215-225. Ed. by G. W. Barrett, and R. Rosenberg. Wiley, Chichester. 305 pp. 
Belley, R., Archambault, P., Sundby, B., Gilbert, F., and Gagnon, J.-M. 2010. Effect of hypoxia onbenthic macrofauna and bioturbation in the Estuary and Gulf of St. Lawrence, Canada. Continental Shelf Research, $30: 1302-1313$.

Birchenough, S.N.R., Parker, E. R., McManus, E., and Barry, J. 2012. Combining bioturbation and redox metrics: potential tools for assessing seabed function. Ecological Indicators, 12, 8-16.

Birchenough, S.N.R.., Bolam, S. G., \& Parker, R. E. (2013). SPI-ing on the seafloor: characterising benthic systems with traditional and in situ observations. Biogeochemistry, 113(1-3), 105-117.

Birchenough, S. N. R., Degraer, S., Reiss, H., Degraer, S., Mieszkowska, N., Borja, A., Buhl-Mortensen, L. et al. 2015. Climate change and marine benthos: A review of existing research and future directions. WIREs Clim Change, 6: 203-223. doi: 10.1002/wcc.330

Boyé, A, Grall, J, Thiébaut, É, Legendre, P, Broudin, C, Houbin, C, Le Garrec, et al. 2019. Decadal dynamics of benthic communities at the regional scale. IMBER Future Oceans Conference Booklet, p. 242.

Braeckman, U., Foshtomi, M. Y., Van Gansbeke, D., Meysman, F., Soetaert, K., Vincx M., and Vanaverbeke, J. 2014. Variable importance of macrofaunal functional biodiversity for biogeochemical cycling in temperate coastal sediments. Ecosystems, 17: 720-737. https://doi.org/10.1007/s10021-014-9755-7.

Breiman, L. 2001. Random forests. Machine Learning, 45: 5-32.

Breine, N. T., De Backer, A., Van Colen, C., Moens, T., Hostens, K., and Van Hoey, G. 2018. Structural and functional diversity of soft-bottom macrobenthic communities in the Southern North Sea. Estuarine, Coastal and Shelf Science, 214: 173-184. https://doi.org/10.1016/j.ecss.2018.09.012

Brey, T. 2001. Population dynamics in benthic invertebrates. A virtual handbook.Version 01.2. http://www.thomas-brey.de/science/virtualhandbook

Brylinski, J. M., Lagadeuc, Y., Gentilhomme, V., Dupont, J.-P., Lafite, R., Dupeupleet, P. A., Huaultal, M. F. et al. 1991. Le fleuve côtier, un phénomène hydrologique important en Manche orientale (exemple du Pas-de-Calais). Oceanologica Acta, 11: 197-203.

Calder-Potts, R. N., Spicer, J. I., Calosi, P., Findlay, H. S., Queirós, A. M., and Widdicombe, S. 2018. Densitydependent responses of the brittlestar Amphiura filiformis to moderate hypoxia and consequences for nutrient fluxes. Marine Ecology Progress Series, 594: 175-191. https://doi.org/10.3354/meps12503 
Cozzoli, F., Bouma, T.J., Ottolander, P., Lluch, M. S., Ysebaert, T. and Herman, P. M. J. 2018. The combined influence of body size and density on cohesive sediment resuspension by bioturbator. Scientific Reports 8: 3831. doi: 10.1038/s41598-018-22190-3

Dannheim, J. R., and Rumohr, H. 2012. The fate of an immigrant: Ensis directus in the eastern German Bight. Helgoland Marine Research, 66: 307-17. https://doi.org/10.1007/s10152-011-0271-2

Dargahi, B., Kolluru, V., and Cvetkovic, V. 2017. Multi-Layered Stratification in the Baltic Sea: Insight from a Modelling Study with Reference to Environmental Conditions. Journal of Marine Science and Engineering, 5: 2. doi:10.3390/jmse5010002

Darr, A., Gogina, M., and Zettler, M. L. 2014. Detecting hot-spots of bivalve biomass inthe south-western Baltic Sea. Journal of Marine Systems, 134: 69-80.

de Bello, F., Lepš, J., Lavorel, S., and Moretti, M. 2007. Importance of species abundance for assessment of trait composition: an example based on pollinator communities. Community Ecology, 8(2): 163-170.

Degraer, S., Wittoeck, J., Appeltans, W., Cooreman, K., Deprez, T., Hillewaert, H., Hostens, K., et al. 2006. The macrobenthos atlas of the Belgian part of the North Sea. Belgian Science Policy, Brussels. 164 pp.

Dethier, M. N., and Berry, H. D. 2012. Puget Sound Intertidal Biotic Community Monitoring. 2011 Monitoring Report. University of Washington, Olympia, WA. 75 pp.

Eklöf, J., Austin, Å., Bergström, U., Donadi, S., Eriksson, B.D.H.K., Hansen, J., and Sundblad, G. 2017. Size matters: relationships between body size and body mass of common coastal, aquatic invertebrates in the Baltic Sea. PeerJ, 5: e2906. https://doi.org/10.7717/peerj.2906.

EMODnet Seabed Habitats portal (http://www.emodnet.eu/seabed-habitats) accessed on 6 September 2016.

Endler, M., Endler, R., Bobertz, B., Leipe, T., and Arz, H.W. 2015. Linkage between acoustic parameters and seabed sediment properties in the south-western Baltic Sea. Geo-Marine Letters, 35 : 145-160.

Foveau, A., Vaz, S., Desroy, N., and Kostylev, V. E. 2017. Process-driven and biological characterisation and mapping of seabed habitats sensitive to trawling. PLoS ONE 12(10): e0184486. https://doi.org/10.1371/journal.pone.0184486

Franklin, J., and Miller, J. A. 2010. Mapping species distributions: Spatial inference and prediction. Cambridge University Press, New York. 320 pp. https://doi.org/10.1017/CBO9780511810602 
Friedland, R., Neumann, T., and Schernewski, G. 2012. Climate change and the Baltic Sea Action Plan: model simulations on the future of the western Baltic Sea. Journal of Marine Systems, 105-108: 175-186. Galanidi, M., Kaboglu, G. and Bizsel, K. C. 2016. Predicting the Composition of Polychaete Assemblages in the Aegean Coast of Turkey. Frontiers in Marine Science, 3: 154. doi: 10.3389/fmars.2016.00154

Callaway, R., Alsvåg, J., de Boois, I., Cotter, J., Ford, A., Hinz, H., Jennings, S.; Kröncke, I., et al. 2002. Diversity and community structure of epibenthic invertebrates and fish in the North Sea. ICES Journal of Marine Science, 59 : 1199-1214.

Gamfeldt, L., Lefcheck, J.S., Byrnes, J.E.K., Cardinale, B.J., Duffy, J.E., Griffin, J.N., 2015. Marine biodiversity and ecosystem functioning: what's known and what's next? Oikos, 124: 252-265.

Ghertsos, K. 2002. Structure spatio-temporelle des peuplements macrobenthiques de la Baie de Seine à plusieurs échelles d'observation. Thèse de doctorat, Université des Sciences et Technologies de Lille.

Godbold, J.A., Hale, R., Wood, C.L., and Solan, M. 2017. Vulnerability of macronutrients to the concurrent effects of enhanced temperature and atmospheric $\mathrm{pCO}_{2}$ in representative shelf sea sediment habitats. Biogeochemistry, 135: 89-102. doi:10.1007/s10533-017-0340-y

Gogina, M., Lipka, M., Woelfel, J., Liu, B., Morys, C., Böttcher, M. E., and Zettler, M. L. 2018. In search of a field-based relationship between benthic macrofauna and biogeochemistry in a modern brackish coastal sea. Frontiers in Marine Science, 5: 489. doi: 10.3389/fmars.2018.00489

Gogina, M., Morys, C., Forster, S., Gräwe, U., Friedland, R., and Zettler, M. L. 2017. Towards benthic ecosystemfunctioning maps: quantifying bioturbation potential in the German part of the Baltic Sea. Ecological Indicators, 73: 574-588. doi: 10.1016/j.ecolind.2016.10.025

Gray, J. S., and Elliott, M. 2009. Ecology of marine sediments: from science to management. Oxford University Press, Oxford. 225 pp.

Gräwe, U., Naumann, M., Mohrholz, V., and Burchard, H. 2015. Anatomizing one of the largest saltwater inflows into the Baltic Sea in December 2014. Journal of Geophysical Research: Oceans, 120 : 7676-7697. Griffiths, J. R., Kadin, M., Nascimento, F. J. A., Tamelander, T., Törnroos, A., Bonaglia, S., Bonsdorff, E., et al. 2017. The importance of benthic-pelagic coupling for marine ecosystem functioning in a changing world. Global Change Biology, 23 : 2179-2196. https://doi.org/10.1111/gcb.13642

Groemping, U. 2006. Relative Importance for Linear Regression in R: The Package relaimpo. Journal of Statistical Software, 17: 1. Downloadable at http://www.jstatsoft.org/v17/i01 
Haider, F., Sokolov, E.P., Timm, S., Hagemann, M., Blanco Rayón, E., Marigómez, I., Izagirre, U., et al. 2019. Interactive effects of osmotic stress and burrowing activity on protein metabolism and muscle capacity in the soft shell clam Mya arenaria. Comparative Biochemistry and Physiology Part A: Molecular \& Integrative Physiology, 228: 81-93. doi: 10.1016/j.cbpa.2018.10.022.

Hale, R., Godbold, J.A., Sciberras, Dwight, JM., Wood C., Hiddink, J. G., and Solan, M. 2017. Mediation of macronutrients and carbon by post-disturbance shelf sea sediment communities. Biogeochemistry, 135: 121-133. doi :10.1007/s10533-017-0350-9

Hale, R., Mavrogordato, M.N., Tolhurst, T.J., and Solan, M. 2014. Characterizations of how species mediate ecosystem properties require more comprehensive functional effect descriptors. Sci. Rep. 4, 6463. doi:10.1038/srep06463

Heip, C., Basford, D., Craeymeersch, J. A., Dewarumez, J. M., Dörges, J., de Wilde, P., et al. 1992. Trends in biomass, density and diversity of North Sea: macrofauna. ICES Journal of Marine Science, 49: 13-22.

Hinz, H., Bergmann, M., Shucksmith, R., Kaiser, M. J., Rogers, S. I. 2006. Habitat association of plaice, sole, and lemon sole in the English Channel. ICES Journal of Marine Science, 63(5): 912-927. https://doi.org/10.1016/j.icesjms.2006.03.011

Hofmann, E. E. and the IMBeR Scientific Steering Committee (eds.) 2016. IMBeR 2016-2025: Science Plan and Implementation Strategy. IMBeR International Project Office, Bergen, Norway.

http://bio-50.io-warnemuende.de/secos Baltic Sea Atlas, accessed online 24 April 2016.

Kim, S. 2015. ppcor: An R Package for a Fast Calculation to Semi-partial Correlation Coefficients. Communications for Statistical Applications and Methods, 22(6): 665-674.

Klingbeil, K., Mohammadi-Aragh, M., Gräwe, U., and Burchard, H. 2014. Quantification of spurious dissipation and mixing-discrete variance decay in a finite-volume framework. Ocean Modelling, 81: 4964.

Kristensen, E., Penha-Lopes, G., Delefosse, M., Valdemarsen, T., Quintana, C.O., and Banta, G.T. 2012. What is bioturbation? The need for a precise definition for fauna in aquatic sciences. Marine Ecology Progress Series, 446: 285-302.

Kröncke, I., Reiss, H., Eggleton, J. D., Aldridge, J., Bergman, M. J. N., Cochrane, S., Craeymeersch, J. A., et al. 2011. Changes in North Sea macrofauna communities and species distribution between 1986 and 2000. Estuarine, Coastal and Shelf Science, 94 : 1-15. doi: 10.1016/j.ecss.2011.04.008 
Lancelot, C., Billen, G., and Barth, H. 1991. Dynamics of Phaeocystis blooms in nutrient enriched coastal zones. In Proc 3rd workshop, Plymouth, March 6 to 7, 1990. Water pollution research report, 23, Ed. by C. Lancelot, G. Billen, and H. Barth. E. Guyot, Brussels. 106 pp.

Larsonneur, C., Bouysse, P., and Auffret, J. P. 1982. The supericial sediments of the English Channel and its Western Approaches. Sedimentology, 29: 851-864.

Laurer, W.-U., Naumann, M., Zeiler, M. 2012. Erstellung der Karte zur Sedimentverteilung auf dem Meeresboden in der deutschen Nordsee nach der Klassifikation von Figge (1981). Geopotenzial Deutsche Nordsee, LBEG - BSH - BGR, Hannover/Hamburg. 19 pp.

Leipe, T., Naumann, M., Tauber, F., Radtke, H., Friedland, R., Hiller, A., and Arz, H.W. 2017. Regional distribution patterns of chemical parameters in surface sediments of the south-western Baltic Sea and their possible causes. Geo-Marine Letters, 37(6): 593-606.

Liaw, A., and Wiener, M. 2002. Classification and regression by randomForest. R News, 2: 18-22.

McArdle, B. H., and Anderson, M.J., 2001. Fitting multivariate models to semi-metric distances: a comment on distance-based redundancy analysis. Ecology, 82: 290-297.

Melin, F. 2013. EMIS - SeaWiFS Monthly climatology primary production (4km) in gC. $\mathrm{m}^{\wedge}-2$. day^-1. European Commission, Joint Research Centre (JRC) [Dataset] PID: http://data.europa.eu/89h/318b08ddf7bd-4be8-9abf-8b9575bde21f

Mermillod-Blondin, F. 2011. The functional significance of bioturbation and biodeposition on biogeochemical processes at the water-sediment interface in freshwater and marine ecosystems. Journal of the North American Benthological Society, 30 : 770-778. doi: 10.1899/10-121.1

Meyer, J., Nehmer, P., and Kröncke, I. 2019. Shifting south-eastern North Sea macrofauna bioturbation potential over the past three decades: a response to increasing SST and regionally decreasing food supply. Marine Ecology Progress Series, 609: 17-32. https://doi.org/10.3354/meps12802

Middelburg, J. J., and Levin, L. A. 2009. Coastal hypoxia and sediment biogeochemistry. Biogeosciences, 6: 1273-1293. https://doi.org/10.5194/bg-6-1273-2009

Montereale-Gavazzi, G., Roche, M., Lurton, X., Degrendele, K., Terseleer, N., and Van Lancker, V. 2018. Seafloor change detection using multibeam echosounder backscatter: case study on the Belgian part of the North Sea. Marine Geophysical Research, 39: 229-247. 
Morys, C., Forster, F., and Graf, G. 2016. Variabilty of bioturbation in various sediment types and on different spatial scales in the southwestern Baltic Sea. Marine Ecology Progress Series, 557: 31-49.

Nechad, B., Ruddick, K., and Neukermans, G. 2009. Calibration and validation of a generic multisensor algorithm for mapping of turbidity in coastal waters. SPIE "Remote Sensing of the Ocean, Sea Ice, and Large Water Regions" Conference held in Berlin (Germany), 31 August 2009. Proceedings of SPIE, 7473: $74730 \mathrm{H}$.

Nechad, B., Ruddick, K., and Park, Y. 2010. Calibration and validation of a generic multisensor algorithm for mapping of total suspended matter in turbid waters. Remote Sensing of Environment, 114: 854-866. Nuñez-Riboni, I., and Akimova, A. 2015. Monthly maps of optimally interpolated in situ hydrography in the North Sea from 1948 to 2013. Journal of Marine Systems, 151: 15-34. DOI:10.1016/j.jmarsys.2015.06.003

Paterson, D. M., Defew, E. C., and Jabour, J. 2012. Ecosystem functioning and co-evolution of terminology in marine science and management. In Marine Biodiversity and Ecosystem Functioning: Frameworks, Methodologies, and Integration, eds. M. Solan, R.J. Aspden, and D.M. Paterson. (Oxford: Oxford University Press), 24-33.

Pittman, S. J. 2018. Seascape Ecology. John Wiley \& Sons, Hoboken, NJ. 528 pp.

Queirós, A. M., Birchenough, S. N. R., Bremner, J., Godbold, J. A., Parker, R. E., Romero-Ramirez, A., Reiss, H., et al. 2013. A bioturbation classification of European marine infaunal invertebrates. Ecol. Evol. 3, 39583985.

Queirós, A.M., Stephens, N., Cook, R., Ravaglioli, C., Nunes, J., Dashfield, S., Harris, C., et al. 2015. Can benthic community structure be used to predict the process of bioturbation in real ecosystems? Progr. Oceanogr. 137, 559-569.

R Core Team, 2013. R: A language and environment for statistical computing. RFoundation for Statistical Computing, Vienna, Austria. <http://www.R-project.org/>.

Reiss, H., Birchenough, S., Borja, A., Buhl-Mortensen, L., Craeymeersch, J.,Dannheim, J., Darr, A., et al. 2015. Benthos distribution modelling and its relevance for marine ecosystem management. ICES Journal of Marine Science, 72, 297-315. 
Renz, J. R., Powilleit, M., Gogina, M., Zettler, M. L., Morys, C., and Forster, S. 2018. Community bioirrigation potential (BIPc), an index to quantify the potential for solute exchange at the sediment-water interface. Marine Environmental Research, 141: 214-224. doi: 10.1016/j.marenvres.2018.09.013

Ricciardi, A., and Bourget, E. 1998. Weight-to-weight conversion factors for marine benthic macroinvertebrates. Marine Ecology Progress Series, 171: 245-251.

S.H.O.M. 1968. Courants de marée dans la Manche et sur les côtes françaises de l'Atlantique, 550. Imprimerie Nationale, Paris. 292 pp.

Savage, S.L., Lawrence, R.L., and Squire, J.R. 2015. Predicting relative species composition within mixed conifer forest pixels using zero-inflated models and Landsat imagery. Remote Sensing of Environment, 171: 326-336.

Schernewski, G., Friedland, R., Carstens, M., Hirt, U., Leujak, W., Nausch, G., Neumann, T., et al. 2015. Implementation of European marine policy: new water quality targets for German Baltic water. Marine Policy, 51: 305-321.

Schlüter, M., and Jerosch, K. 2009. Digital Atlas of the North Sea. Alfred Wegener Institute for Polar and Marine Research. hdl:10013/epic.34893

Sciberras, M., Tait, K., Brochain, G., Hiddink, J. G., Hale, R., Godbold, J.A., and Solan, M. 2017. Mediation of nitrogen by post-disturbance shelf communities experiencing organic matter enrichment. Biogeochemistry, 135: 135-153. https://doi.org/10.1007/s10533-017-0370-5

Snelgrove, P. V. R., Soetaert, K., Solan, M., Thrush, S., Wei, C.-L., Danovaro, R., Fulweiler, R. W., et al. 2018. Global carbon cycling on a heterogeneous seafloor. Trends in Ecology \& Evolution, 33, 96-105. doi: 10.1016/j.tree.2017.11.004

Snelgrove, P. V. R., Thrush, S. F., Wall, D. H., and Norkko, A. 2014. Real world biodiversity-ecosystem functioning: a seafloor perspective. Trends in Ecology \& Evolution, 29(7): 398-405. http://dx.doi.org/10.1016/j.tree.2014.05.002

Soetaert, K., Herman, P. M., Middelburg, J. J., Heip, C., deStigter, H. S., van Weering, T. C. E., Epping, E., et al. 1996. Modelling 210Pb-derived mixing activity in ocean margin sediments: diffusive versus nonlocal mixing. Journal of Marine Research, 54: 1207-1227.

Solan, M., Cardinale, B. J., Downing, A. L., Engelhardt, K. A. M., Ruesink, J. L., and Srivastava,D. S. 2004. Extinction and ecosystem function in the marine benthos. Science, $306: 1177-1180$. 
Solan, M., Scott, F., Dulvy, N.K., Godbold, J.A., and Parker, R. 2012. Incorporating extinction risk and realistic biodiversity futures: implementation of trait-based extinction scenarios, in: Solan, M. (Ed.), Marine biodiversity and ecosystem functioning: Frameworks, methodologies, and integration. Oxford University Press, Oxford, pp. 127-148.

Solan, M., Ward, E. R., White, E. L., Hibberd, E. E., Cassidy, C., Schuster, J. M., Hale, R., et al. 2019. Worldwide measurements of bioturbation intensity, ventilation rate, and the mixing depth of marine sediments. Scientific Data, 6: 58. https://doi.org/10.1038/s41597-019-0069-7

Stanev, E. V., Dobrynin, M., Pleskachevsky, A., Grayek, S., Guenther, H. 2008. Bed shear stress in the southern North Sea as an important driver for suspended sediment dynamics. Ocean Dynamics, 59(2): 183-194. DOI: 10.1007/s10236-008-0171-4

Stips, A., Bolding, K., Pohlmann, T., and Burchard, H. 2004. Simulating the temporal and spatial dynamics of the North Sea using the new model GETM (general estuarine transport model). Ocean Dynamics, 54: 266-283.

Strong, J.A., Andonegi, E., Bizsel, K.C., Danovaro, R., Elliott, M., Franco, A., Garces, E., Little, S., Mazik, K., Moncheva, S., Papadopoulou, N., Patrício, J., Queirós, A.M., Smith, C., Stefanova, K., Solaun, O., 2015. Marine biodiversity and ecosystem function relationships: The potential for practical monitoring applications. Estuarine, Coastal and Shelf Science, 161: 46-64. doi.org/10.1016/j.ecss.2015.04.008

Szostek, C. L., Murray, L. G., Bell, E., Rayner, G., and Kaiser, M. J. 2016. Natural vs. fishing disturbance: drivers of community composition on traditional king scallop, Pecten maximus, fishing grounds. ICES Journal of Marine Science, 73: i70-i83. https://doi.org/10.1093/icesjms/fsv152

Tauber, F. 2012. Meeresbodenrelief in der deutschen Ostsee / Seabed relief in the German Baltic Sea. Hamburg, Rostock: Bundesamt fur Seeschifffahrt undHydrographie. 9 Map Sheets. <http://www.bsh.de/de/Produkte/Karten/.

Tauber, F. 2012. Meeresbodensedimente in der deutschen Ostsee / Seabed sediments in the German Baltic Sea. Hamburg, Rostock: Bundesamt furSeeschifffahrt und Hydrographie. 9 Map Sheets. <http://www.bsh.de/de/Produkte/Karten/Geologische Karten/index.jsp>.

Thomsen, M. S., Garcia, C., Bolam, S. G., Parker, R., Godbold, J. A., and Solan, M. 2017. Consequences of biodiversity loss diverge from expectation due to post-extinction compensatory responses. Scientific Reports 7: 43695. doi: 10.1038/srep43695 
Thomsen, M. S., Godbold, J. A., Garcia, C., Bolam, S. G., Parker, R., and Solan, M. 2019. Compensatory responses can alter the form of the biodiversity-function relation curve. Proceedings of the Royal Society B, 286: 20190287. doi.org/10.1098/rspb.2019.0287

van Bennekom, A. J., and Wetsteijn, F. J. 1990. The winter distribution of nutrients in the Southern Bight of the North Sea (1961-1978) and in the estuaries of the Scheldt and the Rhine/Meuse. Netherlands Journal of Sea Research, 25: 75- 87.

Van Colen, C., Rossi, F., Montserrat, F., Andersson, M. G., Gribsholt, B, Herman, P. M., Degraer S, et al. 2012. Organism-sediment interactions govern post-hypoxia recovery of ecosystem functioning. PLoS One, 7(11): e49795. doi: 10.1371/journal.pone.0049795

Van Hoey, G., Degraer, S., and Vincx, M. 2004. Macrobenthic community structure of soft-bottom sediments at the Belgian Continental Shelf. Estuarine Coastal and Shelf Science, 59: 599-613.

Van Lancker, V. R. M., Verfaillie, E., Schelfaut, K., Du Four, I., and van den Eynde, D. 2007. Marebasse mapping data: GIS in support of Studies and Environmental Assessment. Version 1.0. Belgian Science Policy. Brussel. 8 pp. $+1 \mathrm{dvd}$.

Verfaillie, E., Degraer, S., Schelfaut, K., Willems, W., and Van Lancker, V. 2009. A protocol for classifying ecologically relevant marine zones, a statistical approach. Estuarine, Coastal and Shelf Science, 83(2): 175185. dx.doi.org/10.1016/j.ecss.2009.03.003

Verfaillie, E., Van Lancker, V., Van Meirvenne, M., 2006. Multivariate geostatistics for the predictive modelling of the surficial sand distribution in shelf seas. Continental Shelf Research, 26(19): 2454-2468.

Wei, C. L., Rowe, G. T., Escobar-Briones, E., Boetius, A., and Soltwedel, T. 2010. Globalpatterns and predictions of seafloor biomass using Random Forests. PLoS One, 5(12): e15323.

Wentworth, C. K. 1922. A Scale of Grade and Class Terms for Clastic Sediments. The Journal of Geology, 30(5): 377-392. https://doi.org/10.1086/622910

Wohlgemuth, D., Solan, M., and Godbold, J. A. 2016. Specific arrangements of species dominance are more influential than evenness in maintaining ecosystem properties. Scientific Reports, 6: 39325. 10.1038/srep39325.

Wohlgemuth, D., Solan, M., and Godbold, J. A. 2017. Species contributions to ecosystem process and function can be population dependent and modified by biotic and abiotic setting. Proceedings of the Royal Society, 284(1855): 20162805. http://dx.doi.org/10.1098/rspb.2016.2805 
Wrede, A. , Beermann, J. , Dannheim, J. , Gutow, L., and Brey, T. 2018. Organism functional traits and ecosystem supporting services - A novel approach to predict bioirrigation. Ecological Indicators, 91: 737743. doi:10.1016/j.ecolind.2018.04.026

Wrede, A. , Dannheim, J. , Gutow, L. and Brey, T. 2017. Who really matters: Influence of German Bight key bioturbators on biogeochemical cycling and sediment turnover. Journal of Experimental Marine Biology and Ecology, 488 : 92-101.

Yang, L. 1998. Modelling of hydrodynamic processes in the Belgian Coastal Zone. PhD thesis, Katholieke Universiteit Leuven.

Zeppilli, D., Pusceddu, A., Trincardi, F., Danovaro, R., 2016. Seafloor heterogeneity influences the biodiversity-ecosystem functioning relationships in the deep sea. Nature Scientific Reports, 6: 26352. doi: 10.1038/srep26352

Zettler, M. L., Friedland, R., Gogina, M., and Darr, A. 2017. Variation in benthic long-term data of transitional waters: is interpretation more than speculation? PLoS ONE, 12: e0175746. doi: 10.1371/journal.pone.0175746

Zettler, M. L., Beermann, J., Dannheim, J., Ebbe, B., Grotjahn, M., Günther, C.-P., Gusky, M., et al. 2018. An annotated checklist of macrozoobenthic species in German waters of the North and Baltic Seas. Helgoland marine Research, 72(5): 1-10. 